\title{
Green Profit Maximization through Integrated Pricing and Production Planning for a Line of New and Remanufactured Products
}

\author{
Minjung Kwak ${ }^{1}$ and Harrison $\mathrm{Kim}^{2 *}$ \\ ${ }^{1}$ Department of Industrial and Information Systems Engineering \\ Soongsil University \\ 369 Sangdo-ro, Dongjak-gu, Seoul, South Korea (156-743) \\ 2 Department of Industrial and Enterprise Systems Engineering \\ University of Illinois at Urbana-Champaign \\ 117 Transportation Bldg., 104 S. Mathews Ave., Urbana, IL61801, USA
}

\begin{abstract}
To achieve a "green profit" in their businesses, original equipment manufacturers (OEMs) who produce both new and remanufactured products must optimize their pricing and production decisions. They must determine the buyback price and takeback quantity of end-of-life products (i.e., supply) as well as the selling prices and production quantities of new and remanufactured products (i.e., demand). Detailed production plans for matching the supply and demand should be optimized as well. This paper addresses the lack of a model to deal with buyback pricing, sales pricing, and production planning in an integrated manner. Considering their mutual dependence, the total profit cannot be maximized without optimizing all three simultaneously. This paper presents a model for integrated pricing and production planning for a line of new and remanufactured products in a competitive market. A mixed-integer programming model is proposed that assumes a buyback program as a takeback strategy and optimizes the buyback prices, selling prices, and detailed production plans simultaneously. A transition matrix is used to coordinate pricing and production planning reflecting the design of products. The main objective is to maximize the total profit, but the model also considers how much environmental impact can be avoided by remanufacturing. With the help of the model, OEMs can identify an optimal line of new and remanufactured products that can maximize their total profit while achieving environmental-impact saving greater than a target. By enforcing incrementally increasing environmental targets, OEMs can also explore multiple green profit opportunities that can create greater profits and increased environmental-impact savings than producing new products only. To demonstrate the proposed model, this paper presents a case study with a smartphone example.
\end{abstract}

Keywords: remanufacturing, green design, environmental impact, pricing and production planning

\footnotetext{
* Associate Professor. Author of correspondence. Phone: (217) 265-9437, Fax: (217) 244-5705, Email: hmkim@illinois.edu. An earlier version of the paper was presented at the ASME 2013 IDETC (Kwak et al., 2013).
} 


\section{Introduction}

For original equipment manufacturers (OEMs), producing both new and remanufactured products can be an effective strategy to achieve "green profit" (i.e., profits generated by an environmentally sustainable business (Kwak, 2013)). Remanufacturing is the ultimate form of recovery that "returns used products (i.e., end-of-life products) to like-new condition by rebuilding and replacing their component parts (Ijomah, 2002).” As parts are reused, the same product offering the same quality and performance can be made at only a small fraction of the original cost, with a reduced adverse environmental impact (e.g., natural resource depletion, greenhouse gas emission, and air and water pollution) (Fleischmann, 1997; Hatcher et al., 2011). Remanufactured products enable OEMs to strengthen their product portfolio. By offering a more affordable, greener alternative to their brand-new product, OEMs can span a wider range of the market, in comparison to producing new products only (Atasu et al. 2010; Guide and Li,

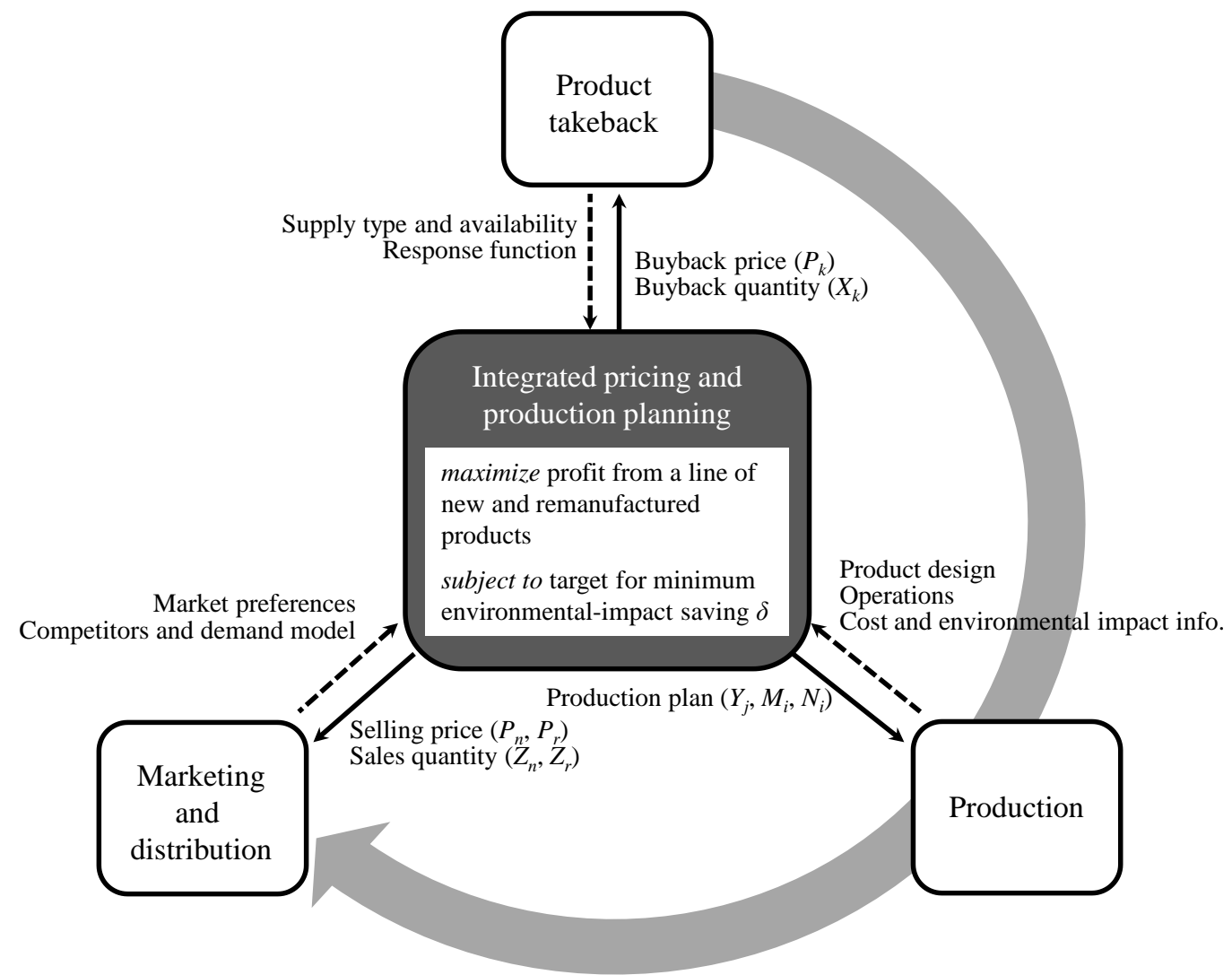

Figure 1. Proposed model for integrated pricing and production planning: inputs and outputs 
2010).

OEMs, however, have a concern with a line of new and remanufactured products, namely, the effect of remanufacturing on the sales of new products. Many OEMs speculate that offering remanufactured products will cannibalize their new product sales, and the threat of cannibalization has been highlighted as a major barrier to the growth of remanufacturing. (Guide and Li, 2010; Atasu et al., 2010). Decision-making tools that can help OEMs increase profits from remanufacturing that outweigh losses from demand cannibalization, are thus required.

As Figure 1 shows, producing a line of new and remanufactured products encompasses three sequential activities: product takeback, production, and marketing and distribution (Geyer and Jackson, 2004; Guide and Van Wassenhove, 2009). Each of them is vital for the success of product line. Product takeback determines the supply of end-of-life products, while marketing and distribution determine the demand for new and remanufactured products. Production achieves the required level of production with available resources. To match the supply and demand, various operations are implemented including disassembly, part reconditioning, and spare procurement. Since all three activities greatly affect the total profit, they have been of considerable interest to researchers for many years. A great deal of research has been conducted on pricing and production planning to optimize each activity. Some researchers have focused on optimizing operations in production (e.g., Jayaraman, 2006; Kwak and Kim, 2010; Kenné et al., 2012), while some have aimed at optimizing either buyback prices of end-of-life products (e.g., Klausner and Hendrickson, 2000; Liang et al., 2009) or selling prices of new and remanufactured products (e.g., Ferguson and Toktay, 2006; Vorasayan and Ryan, 2006; Atasu et al., 2008; Ovchinnikov, 2011). Previous approaches, however, have a limitation in that they overlooked an important point: the three activities are mutually dependent, so the total profit cannot be maximized without optimizing all three activities simultaneously. 
To facilitate in simultaneous optimization of all three activities, this article proposes a model for integrated pricing and production planning in the form of a mixed-integer programming model. The model considers the case where both new and remanufactured products are offered simultaneously to a competitive market. It is distinguished from other studies, such as Ma et al. (2014), Kwak and Kim (2015), and Aydin et al. (2015a), which optimized the closed loop of new and remanufactured products, i.e., new products in the first life and remanufactured products in the second life sequentially. Figure 1 illustrates the proposed model and its inputs and outputs. The proposed model aims to maximize the total profit from a line of new and remanufactured products. It consists of three components: (1) 'buyback pricing', which determines the buyback prices of end-of-life products and their quantity to take back, which later determines the amount of reusable parts (i.e., supply); (2) 'sales pricing', which determines the selling prices of new and remanufactured products and their quantity to produce (i.e., demand); and (3) 'production planning', which determines the detailed plans for matching the supply and demand, including how the end-of-life products should be disassembled (i.e., disassembly level and sequence) and how many and what kind of parts should be reconditioned, newly procured, or recycled. To the authors' knowledge, this work is the first to integrate and coordinate all three components simultaneously.

Linking detailed production planning with pricing is one of the major contributions of the proposed model. A transition matrix is adopted as a key input for production planning to reflect product design characteristics (i.e., part composition, assembly structure, reusability of parts, and part replacement cost, etc.). A transition matrix has been mainly used for modeling disassembly processes (Lambert, 2002; Kwak et al., 2009), but Kwak and Kim (2010) showed that it is applicable to other remanufacturing processes, such as spare procurement and reassembly. In the proposed model, a more generic, extended version of a transition matrix is presented. It can represent entire remanufacturing 
processes including disassembly, part reconditioning, and reassembly, and can incorporate the reusability of parts and corresponding disassembly yields.

Another contribution of the proposed model is that it reflects the environmental benefit of remanufacturing in optimization. Most previous models have focused on maximizing the economic profit only, and few have included environmental considerations. In addition, in most previous studies on the environmental benefit of remanufacturing, the impact of a remanufactured product has been compared with that of a brand-new product under the assumption of a fixed remanufacturing process. The fact that the environmental impact interrelates with the process (e.g., how many parts are reused, newly purchased, and recycled) and is naturally changed by pricing and production planning has been ignored. The proposed model adopts the concept of environmental-impact saving (first presented by Kwak et al., 2013) to address this issue. Environmental-impact saving measures how much environmental impact can be avoided by remanufactured products, as compared to the case where the same amount of equivalent products with the same product design are newly produced (Kwak and Kim, 2015). In this paper, the environmental-impact saving is modeled as a function of decisions on pricing and production planning, so the environmental impact can be assessed and validated correctly.

The proposed model enables OEMs to identify the optimal line of new and remanufactured products that will maximize green profits. Here, green profits denote economic profits that accompany positive environmental-impact savings. The model allows OEMs to explore opportunities for increased green profits (hereinafter green profit opportunities) that can increase both profits and environmentalimpact savings compared to producing only new products. By setting a target for minimum environmental-impact saving, OEMs can maximize their total profit while achieving greater than the target environmental-impact savings. If necessary, OEMs can attain greener solutions that will bring more environmental-impact savings, by enforcing incrementally increased targets. 
The rest of this article is organized as follows. Section 2 discusses the relevant literature, followed by the proposed model in Section 3. Section 4 illustrates the application of the model using the example of a smartphone. Section 5 summarizes the article with future research directions.

\section{Literature Review}

As highlighted by many studies including those of Geyer and Jackson (2004) and Guide and Van Wassenhove (2009), remanufacturing is a problem that goes far beyond production. Remanufacturing is impossible without both a supply of end-of-life products and a demand for remanufactured products (Guide, 2003; Umeda, 2006). To maximize the profits from remanufacturing, it is critical to identify a balance between supply and demand. Appropriate pricing and production planning play a central role in achieving this goal.

Setting the buyback prices of end-of-life products is an effective means of controlling the quantity and quality of end-of-life products (Guide and Wassenhove, 2001). To assist in buyback pricing, several models have been developed, including those by Klausner and Hendrickson (2000) and Liang et al. (2009). Pricing of new and remanufactured products is also an effective means of controlling demand. A few models have been introduced for sales pricing, including those by Ferguson and Toktay (2006), Vorasayan and Ryan (2006), Atasu et al. (2008), Ovchinnikov (2011), and Ovchinnikov et al. (2014). These optimize the selling prices and production quantities of new and remanufactured products so as to reduce the negative impact of demand cannibalization and maximize the total profit. Aydin et al. (2015b) includes product attributes in optimization. The selling price and product attributes were optimized simultaneously for a line of remanufactured and new products.

Most previous studies, however, have limitations with respect to their cost models. Their approaches have been based on a simplified cost model, assuming the per-unit production cost of remanufactured products (which is a key input in pricing decisions) as a constant - an average 
remanufacturing cost. However, such simplification is hard to justify in remanufacturing. As Steeneck and Sarin (2013) pointed out, the per-unit production cost of remanufactured products is affected by not only the quantity and quality of end-of-life products but also the quantity of remanufactured products. Therefore, it should be modeled as a function of both prices. This implies that buyback pricing and sales pricing should be simultaneously implemented and coordinated, but they have been addressed separately in previous studies. Pricing decisions should be made in consideration of possible alternatives to remanufacturing processes and their influences on production costs, but the interdependence between pricing and production planning has also been ignored.

Research in the arena of production planning focuses on optimizing the operations and logistics of the remanufacturing process. Examples include the studies by Mangun and Thurston (2002), Imtanavanich and Gupta (2005), Kwak and Kim (2010), Jayaraman (2006), Kang and Hong (2012), Kenné et al. (2012), and Franke et al. (2006). When supply and demand are known, production planning coordinates them at the minimum cost. Decision variables of interest includes: 1) the takeback quantity of end-of-life products, 2) the disassembly levels/sequences and plans for part reconditioning, 3) the quantity and type of spare parts, and 4) the production quantity and type of remanufactured products. Usually, the buyback and selling prices are given as parameters, not as decision variables to optimize. Buyback pricing, sales pricing, and production planning are all interrelated and should be conducted in an integrated manner. Guide et al. (2003) is an exception that addressed both pricing problems simultaneously, but the detailed process of remanufacturing (from disassembly through reconditioning to reassembly) was not incorporated in the model. Accordingly, the model matches the supply and demand at the product level only, not at the part level; in other words, it requires that $N$ units of end-of-life products should be acquired to produce $N$ remanufactured products. Such simplification of production process also renders the model unable to reflect the impact of product design (e.g., part 
composition, disassembly structure, and part reusability) on optimal pricing decisions. Kwak and Kim (2013) is another exception, where the authors optimized both the selling price and production plan for remanufacturing. However, buy-back prices were given as parameters. Kwak (2015) later carried out integrated pricing and production planning for remanufacturing. The buyback price, selling price, and production plan for a remanufactured product were optimized simultaneously. However, cannibalization of new product sales and competition in the market were not taken into account. Also, the model is applicable only to products with a two-level structure (i.e., a product and its subordinate parts), which makes it unsuitable for other products having a more complex structure with multiple levels.

Environmental considerations were also excluded in the model.

\section{Proposed Model}

\subsection{Nomenclature}

\section{Index}

$I=$ = Index set for item (every possible product and part that appears during production), $i \in I$

$J \quad=$ Index set for operation, $j \in J$

$K=\quad=$ Index set for nominal quality level of end-of-life product, $k \in K$

$L \quad=$ Index set for market segment, $l \in L$

Decision variable

$X_{k} \quad=$ Amount of end-of-life product with quality level $k$ to be taken back

$Y_{j} \quad=$ Number of times operation $j$ is executed

$N_{i} \quad=$ Amount of item $i$ to be externally purchased

$M_{i} \quad=$ Amount of item $i$ to be sent for material recovery, respectively

$Z_{n}, Z_{r} \quad=$ Amount of new and remanufactured products to be produced, respectively

Parameter

$T_{i j} \quad=$ Transition matrix entry, the value of cell $(i, j)$

$A_{k} \quad=$ Amount of end-of-life product $k$ that is available for takeback

$s_{k}\left(P_{k}\right) \quad=$ Take-back rate of end-of-life product $k$ given the buyback price of $P_{k}$

$Q_{l} \quad=$ Size of market segment $l$ in unit of product

$d_{n, l}\left(P_{n}, P_{r}\right)=$ Market share of the new product in segment $l$ given the selling prices, $P_{n}$ and $P_{r}$

$d_{r, l}\left(P_{n}, P_{r}\right)=$ Market share of the remanufactured product in segment $l$ given the selling prices, $P_{n}$ and $P_{r}$

$C_{n}, E_{n} \quad=$ Per-unit total cost and environmental impact of producing a new product, respectively 


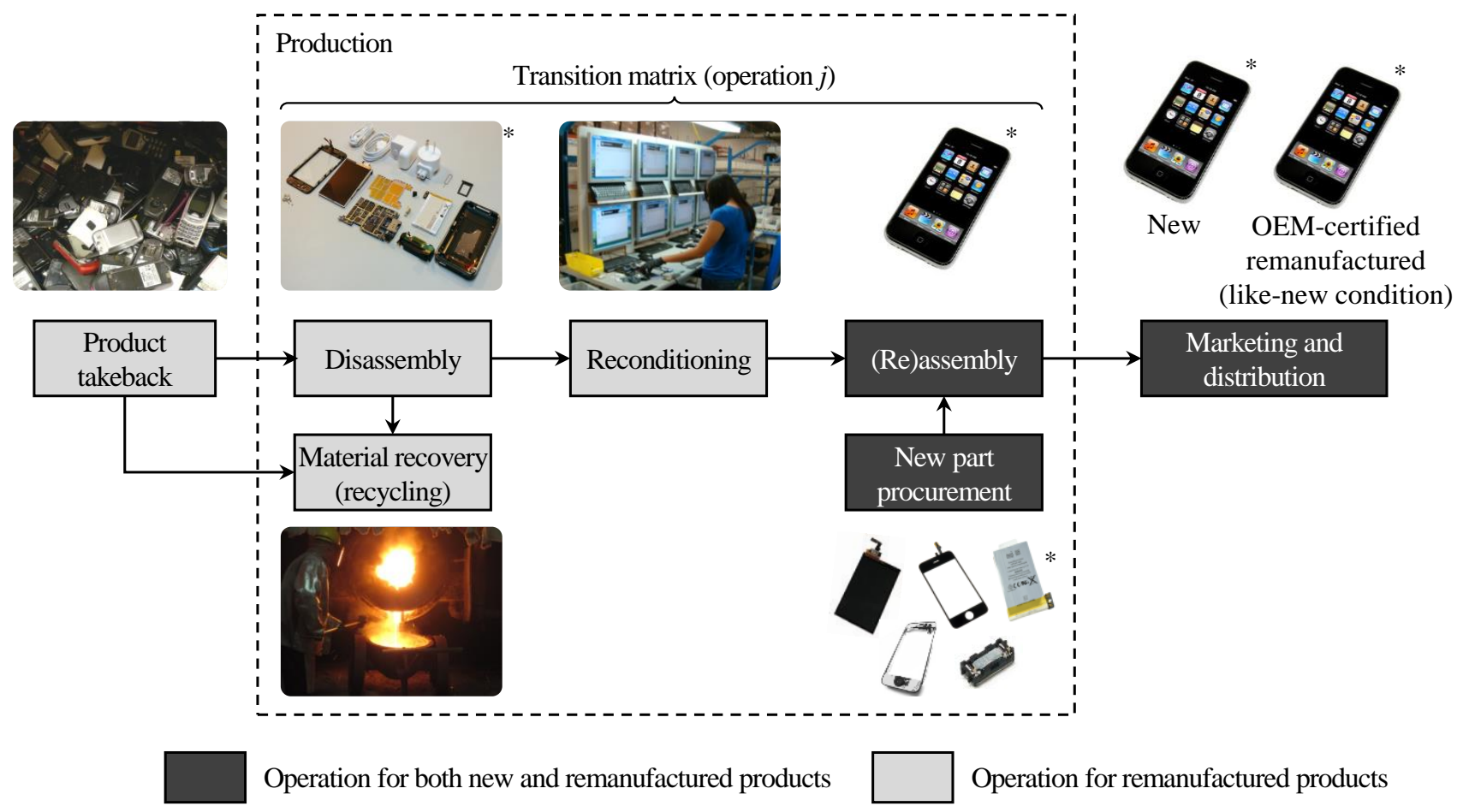

Figure 2. Production process under consideration (*images courtesy of iFixit.com)

$c_{i}^{N}, e_{i}^{N} \quad=$ Per-unit cost and environmental impact of purchasing item $i$, respectively

$c_{i}^{M}, e_{i}^{M}=$ Per-unit cost and environmental impact of recycling item $i$, respectively

$c_{j}, e_{j} \quad=$ Per-unit cost and environmental impact of operation $j$, respectively

$c_{d}, e_{d} \quad=$ Per-unit cost and impact of marketing/distributing a remanufactured product, respectively

$e_{k} \quad=$ Per-unit environmental impact of taking back an end-of-life product $k$

$e_{w} \quad=$ Per-unit environmental impact of an end-of-life product discarded by consumers

$\delta \quad=$ Target for the environmental saving

\subsection{Problem Description: Process Perspective}

The model proposed in this article considers an OEM that produces a line of new and remanufactured products. The company produces $Z_{n}$ and $Z_{r}$ units of new and remanufactured products, respectively, which are distributed to a competitive market and sold at a price of $P_{n}$ and $P_{r}$, respectively. Although the remanufactured product is of the same design and quality as the new product, its label 'remanufactured' results in a selling price different from that of the new product. The objective of the OEM is to maximize the total profit from the product line, while achieving a certain environmental-impact saving 
greater than the target, $\delta$. A single-period planning horizon is considered.

Figure 2 illustrates the overall production process under consideration using the example of a smartphone. It consists mainly of three sequential activities: product takeback, production (in a narrow meaning indicating manufacturing/remanufacturing operations), and marketing and distribution. During production, various operations are conducted to transform the acquired inputs (i.e., end-of-life products, purchased new parts) into the desired output forms (i.e., new and remanufactured products, or feedstock for material recovery).

In Figure 2, the process of producing a new product is represented by dark grey boxes. It involves three operations: new-parts purchase, assembly, and marketing and distribution. Products are assembled from brand-new parts and distributed to the market through forward logistics. The process of remanufacturing additionally involves three preceding operations (represented by light-grey boxes): (1) product takeback, (2) disassembly, and (3) part reconditioning.

Product takeback is the process of collecting end-of-life products. Since product takeback determines the quality and quantity of inputs processed later in production, of major concerns are how many products and what quality of products should be acquired. The proposed model assumes a buyback program as a takeback strategy. According to environmental legislation, consumers can return the end-of-life products to collection sites free of charge in most cases. Without compensation, however, consumers tend to store a product indefinitely even if they no longer use it (Kwak et al. 2011). Buyback price is a means to motivate consumers to return their products early. Although this may increase the takeback cost, a greater number of products with better quality can be secured, which in turn will reduce the production cost at a later stage. In the proposed model, end-of-life products are classified into $k$ groups depending on their quality condition, and buyback prices are determined for each group. (It should be noted, however, that how consumers would react to a certain buyback price, or, the takeback 
probability given a buyback price $P_{k}$, is predefined and given in the form of a function called the 'response function.' Modeling the response function is beyond the scope of this paper.) Given that there exists a total of $A_{k}$ units of end-of-life product available for take back in the market, the OEM actually buys back $X_{k}$ units by paying a price of $P_{k}$ per unit. The remaining $\left(A_{k}-X_{k}\right)$ units are assumed to be discarded by consumers.

After product takeback, the collected $X_{k}$ products pass through remanufacturing operations, starting from disassembly. Disassembly separates an end-of-life product into parts; those parts that are functional and in good condition, or, "that can be brought back to original quality through reconditioning (Hatcher et al., 2011)" are harvested and considered for reuse. In this paper, the term 'part' refers to any decomposable element of a product; it can be either subassemblies or components. 'Subassembly' denotes non-atomic parts of a product at an intermediate level of disassembly structure, which are neither a product nor a component. Through additional steps of disassembly, subassemblies can be separated into child components. 'Component' denotes an atomic part at the lowest level, which cannot be separated any further (Krikke et al. 1998). An important point in disassembly is that not all of the resulting parts are reusable. Also, some of the reusable parts might not be needed if the quantity of reusable parts is sufficient to meet the production quantity $Z_{r}$. In the proposed model, such unused parts are assumed to be sent to recyclers for material recovery. $M_{i}$ denotes the amount of parts heading to recycling.

For the reusable parts to be actually used in remanufacturing, reconditioning operations (e.g., cleaning, re-machining, lubricating, testing) are conducted as needed. After being reconditioned, the parts are reassembled into $Z_{r}$ units of remanufactured products that provide the same quality and performance as brand-new products. When there is a shortage of parts, new parts can be procured externally, as occurs in new-product production. $N_{i}$ denotes the amount of parts newly purchased. 


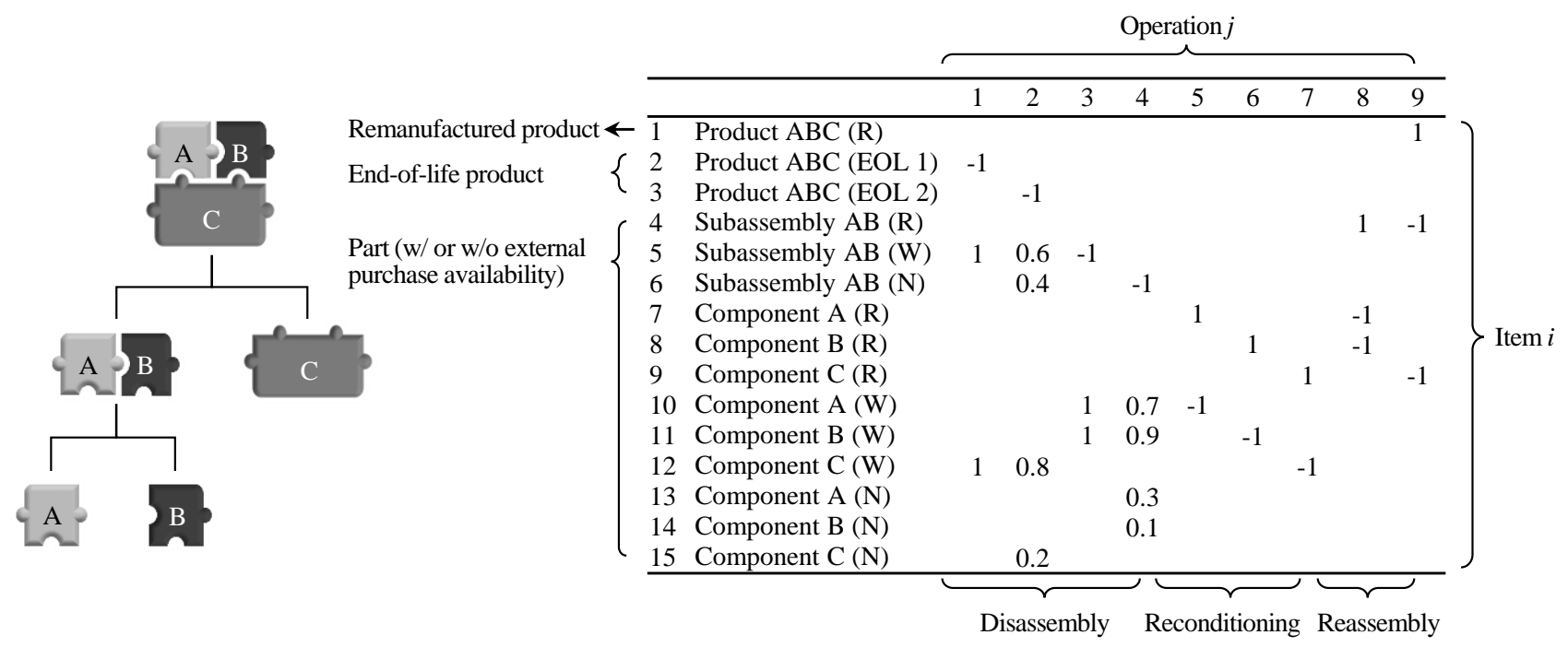

Figure 3. Example product $\mathrm{ABC}$ and its transition matrix

Same as $Z_{n}$ units of new products, $Z_{r}$ units of remanufactured products are distributed to the market through forward logistics. The new and remanufactured products compete with each other, and with other competing products. The demand for each product (the choice probability or the market share) is determined by multiple factors, including the selling price, product performance, and newness (i.e., whether a product is a brand new or remanufactured). In the proposed model, the demand model of the target market is assumed to be given; it is beyond the scope of this study to develop the demand model.

\subsection{Transition Matrix}

For production planning, the proposed model requires a transition matrix as a key input. It represents the relationship between product design and remanufacturing operations in a matrix form, such that the impact of product design can be mathematically reflected in the production planning. In most previous research (Lambert, 2002; Kwak et al. 2009), a transition matrix has been applied to model product disassembly only. The proposed model introduces an advanced version of transition matrix, which can also represent part reconditioning and reassembly. 
Figure 3 shows an example of a transition matrix. An imaginary product ABC, consisting of three components - $\mathrm{A}, \mathrm{B}$, and $\mathrm{C}$ - is taken as the example. The rows of the matrix are related to product design. The term 'item' refers to every possible state of an end-of-life product, or, every possible input/output unit that appears during the production process. An item, $i(i \in I)$, fills a row in the matrix and can be a whole product, a subassembly, or a component from top to bottom. Please note that items are also differentiated by their quality condition. In Figure 3, the letter in parentheses indicates the condition: '(R)' represents 'reconditioned' or 'remanufactured', and '(W)' and '(N)' represent 'working' and 'non-working', respectively. '(EOL1)' and '(EOL2)' are used to indicate two different quality levels of end-of-life products (i.e., good and poor, for example, respectively). The columns of the matrix are related to remanufacturing operations. Each column indicates specific operation $j(j \in J)$ from disassembly through reconditioning to reassembly, from left to right.

A transition matrix shows the input-output material flow of each and every possible remanufacturing operation. In the transition matrix, an operation $j$ is regarded as a transition of items, and the values in the relative column describe the input and output items of the transition. If a cell $(i, j)$ has a value of -1 , it means that an item $i$ is processed (changed to other item(s)) by operation $j$; alternatively, if a cell $(i, j)$ has a value of 1 , it indicates that an item $i$ is generated from operation $j$. If a cell $(i, j)$ has a value of 0 , item $i$ has nothing to do with the operation $j$.

Given the definitions, one can easily interpret a transition matrix. For example, operations 1 through 4 in Figure 3 represent disassembly operations. Operation 1 indicates that a unit of end-of-life product $\mathrm{ABC}$ with good quality is broken down into two parts, a unit of working subassembly $\mathrm{AB}$ and a unit of working component C. Operation 2 represents a more complicated case with probabilistic information about the yield rates (or, part reusability after disassembly). A unit of end-of-life product $\mathrm{ABC}$ with poor quality is separated into subassembly $\mathrm{AB}$ and a component $\mathrm{C}$. The probability that the 
disassembled $\mathrm{AB}$ is working and reusable is $60 \%$, while the remaining $40 \%$ of $\mathrm{AB}$ is non-working. Similarly, $80 \%$ of component $\mathrm{C}$ is working and reusable, whereas $20 \%$ of $\mathrm{C}$ is non-working and should be sent to recyclers for material recovery. Operations 3 and 4 can be interpreted in a similar way.

Operations 5 through 7 indicate reconditioning operations that are conducted for disassembled parts to make them ready for remanufacturing. Only working parts undergo the operations and change the state to reconditioned parts. Operation 5 represents the reconditioning operation for component A. A working component A is transitioned to a reconditioned item with a $100 \%$ yield rate. Similarly, Operations 6 and 7 represent the reconditioning operations for components B and C, respectively.

Operations 8 and 9 show reassembly operations. Operation 8 denotes the assembly operation for subassembly AB. Reconditioned components A and B are combined to make one unit of remanufactured subassembly AB. Operation 9 represents the final operation that makes the remanufactured product $\mathrm{ABC}$ by combining remanufactured subassembly $\mathrm{AB}$ and reconditioned component $\mathrm{C}$.

When a certain number of end-of-life products are given as the initial input to the production system, the output from the system is determined by the number of times each operation $j$ is performed. For instance, suppose that 10 units of end-of-life product $\mathrm{ABC}$ with good quality (EOL1) are taken back. If operation 1 is conducted 5 times, the resulting items are 5 units of product $\mathrm{ABC}$ (EOL1), 5 units of subassembly $\mathrm{AB}(\mathrm{W})$, and 5 units of component $\mathrm{C}(\mathrm{W})$. If operation 3 is conducted additionally 3 times, then the outputs are changed to 5 units of product $\mathrm{ABC}$ (EOL1), 2 units of subassembly $\mathrm{AB}(\mathrm{W}), 3$ units of A (W), 3 units of B (W), and 2 units of C (W). With respect to each item $i$ in a row, this input-output flow can be mathematically modeled as shown in Equation (1), where $T_{i j}$ is the value of cell $(i, j)$ in the transition matrix, and $Y_{j}$ is a decision variable representing the number of times operation $j$ is executed. Input $_{i}$ represents any external supplies of item $i$; i.e., supplies from product takeback or new part purchase. Output ${ }_{i}$ denotes the final throughput of the production system; i.e., either remanufactured 
product or items for material recovery. Since possible inputs and outputs of item $i$ differ by its type, Equation (1) is further varied into four versions depending on the item type, as shown in Equation (2).

$$
\text { Input }_{i}+\sum_{j \in J} T_{i j} \cdot Y_{j}=\text { Output }_{i}
$$

$$
\begin{cases}X_{k}+\sum_{j \in J} T_{i j} \cdot Y_{j}-M_{i}=0 & \forall i \text { corresponding to the end-of-life product } k(\forall k \in K) \\ N_{i}+\sum_{j \in J} T_{i j} \cdot Y_{j}-M_{i}=0 & \forall i \text { corresponding to a part with external purchase availability } \\ \sum_{j \in J} T_{i j} \cdot Y_{j}-M_{i}=0 & \forall i \text { corresponding to a part without external purchase availability } \\ \sum_{j \in J} T_{i j} \cdot Y_{j}-Z_{r}=0 & \forall i \text { corresponding to the remanufactured product }\end{cases}
$$

As proven by many previous studies, a transition matrix brings multiple benefits in production planning. Transition matrix is useful to deal with a problem that involves complex products having multi-level disassembly structures and is distinguished from other approaches that limit the product structure to be either two or three levels (e.g., Jayaraman, 2006; Inderfurth and Langella, 2008). Multiple products can be considered simultaneously, and parts commonality can be incorporated in the modeling (e.g., Kwak and Kim, 2011). Various disassembly sequences can be considered including options for partial, incomplete disassembly (Kwak et al., 2009). The capacity and capability of recovery plants and operations shared by multiple items can be easily reflected in the planning (Behdad et al., 2009; Kwak and Kim, 2010). Moreover, automatic generation of the transition matrix is possible (Kang et al., 2010). Although not all aspects are shown in the proposed model, the model can be easily extended to fully exploit the benefits.

\subsection{Mathematical Model}

Equations (3) through (5) show the proposed model for integrated pricing and production planning. For a single type of product and single-period planning horizon, the model optimizes the following variables, using mixed-integer programming:

- $\quad P_{k}, X_{k}$ : Buyback price and the takeback quantity of end-of-life product $k(\forall k \in K)$ 
- $P_{n}, Z_{n}$ : Selling price and the production quantity of the new product

- $P_{r}, Z_{r}$ : Selling price and the production quantity of the remanufactured product

- $Y_{j}, M_{i}, N_{i}$ : Production plan; number of times of operation, recycling amount, quantity of new parts to procure $(\forall i \in I)$

$\max .\left(P_{n}-C_{n}\right) \cdot Z_{n}+P_{r} \cdot Z_{r}-\left(\sum_{i \in I} c_{i}^{M} \cdot M_{i}+\sum_{k \in K} P_{k} \cdot X_{k}+\sum_{j \in J} c_{j} \cdot Y_{j}+\sum_{i \in I} c_{i}^{N} \cdot N_{i}+c_{d} \cdot Z_{r}\right)$

with respect to $X_{k}, Y_{j}, Z_{n}, Z_{r}, M_{i}, N_{i}, P_{k}, P_{n}, P_{r}(\forall i \in I, \forall j \in J, \forall k \in K)$

$g_{1}: X_{k} \leq A_{k} \cdot s_{k}\left(P_{k}\right) \quad \forall k \in K$

$g_{2}: Z_{n} \leq \sum_{l \in L} Q_{l} \cdot d_{n, l}\left(P_{n}, P_{r}\right)$

$g_{3}: Z_{r} \leq \sum_{l \in L} Q_{l} \cdot d_{r, l}\left(P_{n}, P_{r}\right)$

$\mathrm{g}_{4}: Z_{r} \leq X_{k}$

$g_{5}: \sum_{k \in K}\left(e_{w}-e_{k}\right) \cdot X_{k}+\left\{E_{n} \cdot Z_{r}-\left(\sum_{i \in I} e_{i}^{M} \cdot M_{i}+\sum_{j \in J} e_{j} \cdot Y_{j}+\sum_{i \in I} e_{i}^{N} \cdot N_{i}+e_{d} \cdot Z_{r}\right)\right\} \geq \delta$

$h_{1}: X_{k}+\sum_{j \in J} T_{i j} \cdot Y_{j}-M_{i}=0 \quad \forall i$ corresponding to the end-of-life product $k(\forall k \in K)$

$h_{2}: N_{i}+\sum_{j \in J} T_{i j} \cdot Y_{j}-M_{i}=0 \quad \forall i$ corresponding to a part with external purchase availability

$h_{3}: \sum_{j \in J} T_{i j} \cdot Y_{j}-M_{i}=0 \quad \forall i$ corresponding to a part without external purchase availability

$h_{4}: \sum_{j \in J} T_{i j} \cdot Y_{j}-Z_{r}=0 \quad \forall i$ corresponding to the remanufactured product

$h_{5}: N_{i}=0 \quad \forall i \notin$ part with external purchase availability

$h_{6}: M_{i}=0 \quad \forall i$ corresponding to the remanufactured product

$X_{k}, Y_{j}, Z_{n}, Z_{r}, N_{i} \geq 0$ and integer $\quad \forall i \in I, \forall j \in J, \forall k \in K$

$P_{k}, P_{n}, P_{r}, M_{i} \geq 0 \quad \forall i \in I, \forall k \in K$

Equation (3) represents the objective function, i.e., maximizing the total profit from the sales of new and remanufactured products. It should be noted that no fixed cost is included in the model with an assumption that the OEM (i.e., the decision maker) utilizes an existing facility and infrastructure. The profit from new product sales, therefore, can be modeled as the difference between total revenue and total cost, i.e., $\left(P_{n}-C_{n}\right) \cdot Z_{n}$ where $C_{n}$ denotes the per-unit variable cost of the new product. The variable cost includes the cost of new part purchase, the cost of assembly, and the cost of marketing and distribution. The profit from remanufactured products takes a more complex form, due to its cost 
structure. The total cost is the sum of five cost components: the cost of material recovery, cost of takeback, cost of remanufacturing operations, cost of new part purchase and cost of marketing and distribution.

Equations (4) through (6) list the constraints of the model. Constraint $g_{1}$ presents constraints on product takeback, where $s_{k}\left(P_{k}\right)$ denotes a response function that gives the takeback rate of end-of-life product $k$ given the buyback price of $P_{k}$. In general, the takeback rate $s_{k}\left(P_{k}\right)$ increases monotonically by $P_{k}$. The maximum attainable amount of end-of-life product is $A_{k}$, and it creates the upper limit for the takeback quantity, $X_{k}$. Constraints $g_{2}$ and $g_{3}$ prevent the production quantities $Z_{n}$ and $Z_{r}$ from exceeding the market demand, where the size of market segment $l$ is $Q_{l}$ and the market share of the new and remanufactured products in the segment are given as functions of the selling prices $P_{n}$ and $P_{r}$, i.e., $d_{n, l}\left(P_{n}, P_{r}\right)$ and $d_{r, l}\left(P_{n}, P_{r}\right)$, respectively. Since they are offered to the same market, the price of one product may affect the demand for the other. The functions can be defined through well-known demand modeling techniques, such as conjoint analysis (Green et al., 2001) and discrete choice analysis (BenAkiva and Lerman, 1985; Wassenaar et al., 2003). Constraint $g_{4}$ poses an additional constraint on $Z_{r}$. It requires that $Z_{r}$ does not exceed $X_{k}$.

Constraint $g_{5}$ requires the OEM meet the target $\delta$ for environmental-impact saving. The lefthand side formulates the environmental-impact saving. Environmental-impact savings indicates how much environmental impact can be claimed to be avoided by producing $Z_{r}$ units of remanufactured products, as compared to the reference case when the same amount of equivalent products are newly produced while no takeback is conducted. To be more specific, the environmental-impact saving originates from two sources. First, the amount of waste that must be disposed of is reduced as $X_{k}$ units of end-of-life product $k(\forall k \in K)$ return for remanufacturing. This is modeled by the first term of the constraint. Second, products in 'same-as-new' condition are produced using reduced natural resources 
and energy, as the parts from the end-of-life products are reused. This is modeled by the remaining terms in the left-hand side.

As discussed in Section 3, Constraints $h_{1}$ through $h_{6}$ restrain the input-output flow balance in remanufacturing operations. Constraint $h_{1}$ requires every collected end-of-life product is either disassembled for part recovery or recycled for material recovery. Constraints $h_{2}$ and $h_{3}$ ensure the flow balance of parts. If external purchase is available, new parts can be input to the system to address a shortage of parts. All parts remaining after remanufacturing operations are recycled for material recovery. Constraint $h_{4}$ ensures that the remanufacturing operations produce $Z_{r}$ units of the remanufactured product. Constraint $h_{5}$ allows new part purchase only for items with external procurement availability. Constraint $h_{6}$ removes unrealistic cases in which the remanufactured products are recycled instead of being distributed to the market. Finally, the remaining constraints in Equation (6) represent variable conditions.

\section{Case Illustration}

\subsection{Scenario and Assumptions}

To illustrate the application of the proposed model, this section presents a case study using an example of a smartphone. Suppose that an OEM has been producing only new smartphones. As remanufacturing is emerging as a new business opportunity, the OEM is considering starting their own remanufacturing business in the upcoming period. By offering new and remanufactured products together, the OEM expects to increase their market share and profit. Additionally, the company anticipates that remanufacturing will also improve the environmental sustainability of their business. One concern of the company, however, is the risk of cannibalization. Remanufacturing might hurt sales of new smartphones and may decrease the total profit. Another concern is the degree of actual environmental benefit. Although it is generally claimed that remanufacturing enables a significant environmental-impact 
saving, this has not been validated for their products.

Given this background, the OEM wants to discern (1) whether or not offering the line of new and remanufactured products will be more profitable, (2) whether or not implementing remanufacturing can bring significant environmental-impact saving, and (3) if all of these are true, then what the optimal prices and production plan should be to achieve the maximum profit. To this end, the OEM wants to analyze and compare following two cases by applying the model proposed in Section 3:

- Baseline case (New only): The OEM optimizes the selling price and production quantity of the new smartphone and offers them to the market. No takeback or remanufacturing is conducted. All end-of-life products are assumed to be discarded by consumers. It is estimated that they are either landfilled (80\%) or incinerated (20\%).

- Target case: The OEM optimizes and sells both new and remanufactured smartphones. Integrated pricing and production planning is conducted for the product line. End-of-life smartphones are taken back from the users by paying a positive buyback price. Once collected, the used smartphones are disassembled into parts, and the parts can be reused in remanufacturing after appropriate reconditioning. No identity change (or upgrade) happens in remanufacturing, so the end-of-life products are remanufactured to the same product. Products or parts that remain after remanufacturing will be sold to material scrappers who guarantee recycling rates of $100 \%$ for metals, $6 \%$ for plastics, and $16 \%$ for rubber.

Data Sources. The proposed model requires several input parameters that characterize the product, production operations, and the supply and demand in the market (Figure 1). The parameter values in this case study were derived from multiple data sources.

The design of the smartphone product (including its parts, weight, and material composition) and the per-unit cost of operations were assumed based on Apple (2009), Kwak and Kim (2011), and online repair guides for smartphones (www.iFixit.com). Retail prices of new parts were estimated according to the market prices of similar parts (www. ubreakifix.com). Part reusability was adopted from Kwak and Kim (2011), who estimated the parameters based on the failure reports of a particular smartphone model (SquareTrade, 2008; SquareTrade, 2009). The recycling cost of an item was assigned 
based on its weight and material type. Three different multipliers were used: $\$ 11.02 / \mathrm{kg}$ for logic boards, $\$ 3.31 / \mathrm{kg}$ for batteries, and $\$ 5.51 / \mathrm{kg}$ for any mix of items (www.grn.com; Sodhi and Reimer, 2001). The supply of end-of-life products and the demand for new and remanufactured products were assumed based on the approaches by Klausner and Hendrickson (2000), Kwak et al. (2012), and Kwak and Kim (2013), and based on the actual prices of a particular smartphone in the new product market (www.apple.com), in the second-hand market (www. ebay.com), and in the buy-back market (www.gazelle.com; www. nextworth.com). Regarding the environmental-impact parameters (e.g., $e_{j}, e_{w}$, $e_{k}$ ), a life cycle assessment (LCA) was conducted, and the global warming potential (GWP) was used as a measure of the environmental impact. The GWP quantifies greenhouse gas emissions to air, and the measurement unit is kilograms of carbon dioxide equivalent (hereinafter $\mathrm{kg} \mathrm{CO}_{2}$ equivalent). (Note that the way in which the LCA is performed is beyond the scope of this study; refer to Goedkoop (2000) and Rebitzer et al. (2004) for details on LCA.)

Assumptions on the supply of end-of-life products. Depending on the quality, end-of-life smartphones are divided into two groups: $\operatorname{good}(k=1)$ and poor $(k=2)$. The amounts of end-of-life smartphones available in the market are known to be 3,000 and 5,000 units, respectively (i.e., $A_{1}=3,000, A_{2}=5,000$ ). Figure 4 describes response functions assumed for the end-of-life smartphones. It shows how the

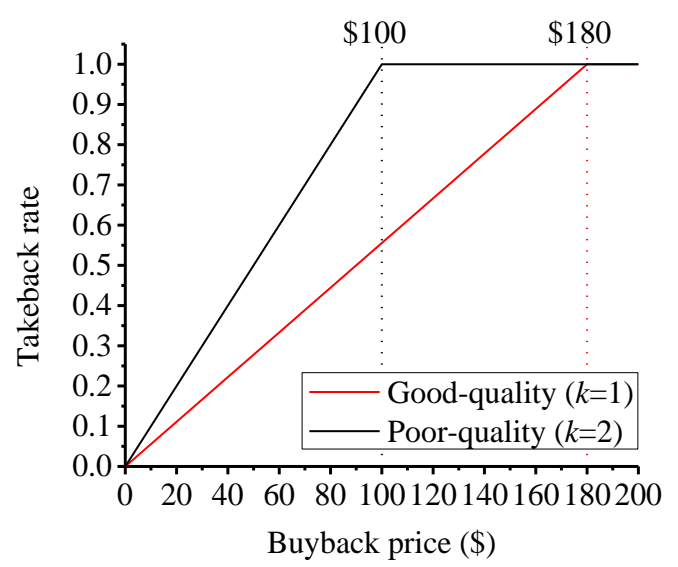

Figure 4. Response function for the end-of-life smartphones 
takeback rates will change depending on buyback prices. It is assumed that the takeback rates linearly increase according to the buyback price and peak at prices of $\$ 180$ (good quality) and $\$ 100$ (poor quality), respectively (Klausner and Hendrickson, 2000; Kwak et al., 2012). Thus the OEM can improve the quantity and quality of end-of-life smartphones by paying higher buyback prices.

Assumptions on product design and operations. Figure 5 shows the end-of-life smartphone under consideration and its disassembly structure (Apple, 2009; Kwak and Kim, 2011; www.iFixit.com). It has a three-level structure consisting of the product, subassembly, and component, from top to bottom. Three subassemblies exist — the front screen assembly (FS), dock connector assembly (DC), and rear panel assembly (RP)—each of which has four child components.

The transition matrix of the smartphone is shown in the Appendix (Table A1). It includes a total of 57 items and 27 transitions (or, operations). Operations 1 through 8 represent disassembly operations. Operations 1 and 2 show disassembly of a product into three subassemblies (i.e., FS, DC, and RP) and three components (i.e., logic board, camera, and battery). Operations 3 through 8 describe disassembly of each subassembly into its child components. Operations 9 through 23 and operations 24 through 27 represent reconditioning and reassembly operations, respectively. Reusing a part requires that all of its components must be disassembled and reconditioned first. Direct reuse of disassembled subassemblies

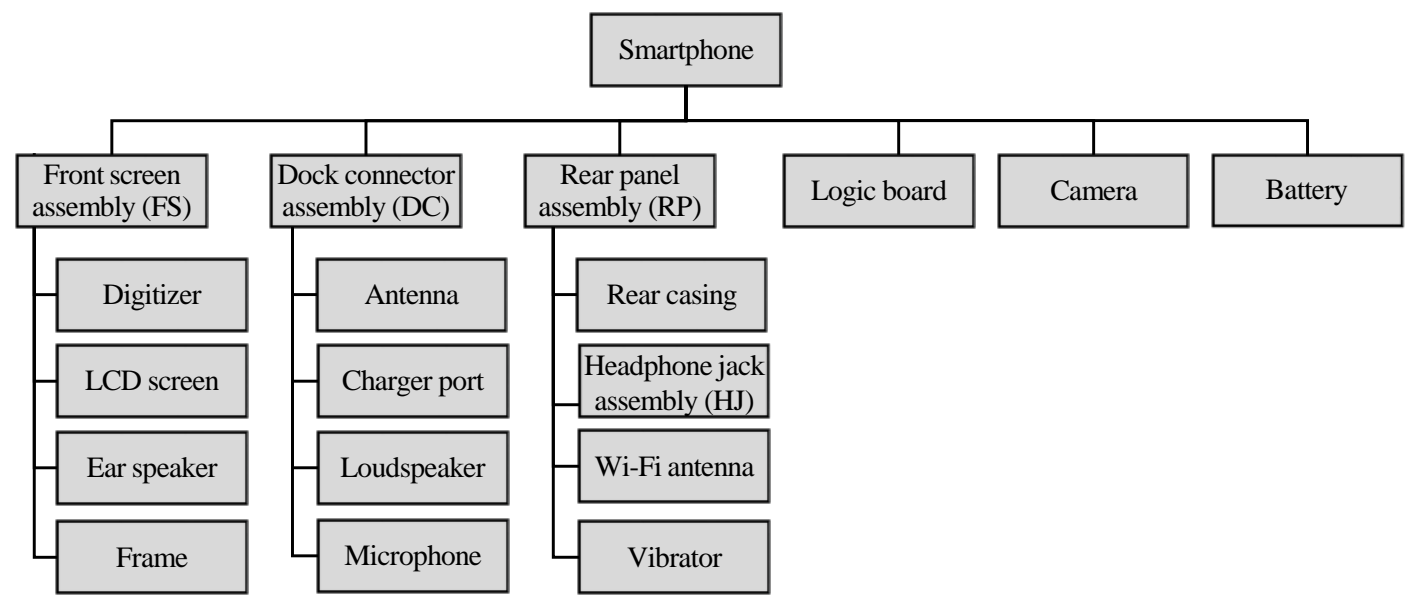

Figure 5. Disassembly structure of the smartphone (redrawn from Kwak and Kim (2011)) 
is not allowed. However, this does not necessarily mean that the product is fully disassembled into components. Partial, incomplete disassembly is possible; non-working subassemblies do not have to be disassembled further. They can proceed to material recovery as they are, with no change in form.

Regarding production cost and environmental impact, it is assumed that the OEM has been producing new smartphones at a cost of $\$ 223$ per unit $\left(C_{n}=223\right)$. The total environmental impact is assumed to be $38.9 \mathrm{~kg} \mathrm{CO}_{2}$ equivalent per unit $\left(E_{n}=38.9\right)$. For every end-of-life, taken-back product, 1.8 $\mathrm{kg} \mathrm{CO}_{2}$ equivalent is caused ( $\left.e_{k}=1.8\right)$. When the end-of-life product is discarded by consumers, the environmental impact increases to $6 \mathrm{~kg} \mathrm{CO}_{2}$ equivalent per unit ( $\left.e_{w}=6\right)$. The impact is set higher as either landfill (80\%) or incineration (20\%) was assumed for discarded products. The per-unit cost and environmental impact of remanufacturing operations are shown in the Appendix. Table A2 provides information on part procurement and material recovery $\left(c_{i}^{N}, e_{i}^{N}, e_{i}^{M}\right.$, and $\left.c_{i}^{M}\right)$, while Table A3 gives details on other remanufacturing operations $\left(c_{j}\right.$ and $\left.c_{d}\right)$.

Assumptions on demand for the new and remanufactured products. Suppose that the market share of a product in the target market is determined by three factors: (1) product performance, (2) selling price, and (3) newness (i.e., whether a product is a brand new or remanufactured). Here, product performance is determined by product design and given as a number between 0 (poorest) and 1 (best performance). The performance of the new and remanufactured smartphones is assumed to be identical and known to be 0.7 .

Table 1 shows the competing products in the target market assumed for the upcoming period. Each product has pros and cons. Competitor 1 is a new product with relatively high performance but most expensive. Competitor 2 is more affordable but its performance is lower than that of Competitor 1. Competitor 3 is the most economical option with high performance. However, it is a remanufactured product and may not be preferred by consumers who care about the newness of a product. 
Table 1. Competing products in the target market

\begin{tabular}{lccc}
\hline & Performance & Price & Newness \\
\hline Competitor 1 & 0.7 & $\$ 800$ & New \\
Competitor 2 & 0.5 & $\$ 500$ & New \\
Competitor 3 & 0.7 & $\$ 400$ & Remanufactured \\
\hline
\end{tabular}

Table 2. Market segments in the target market

\begin{tabular}{cccc}
\hline & Size & Critical price $\left(\bar{P}_{l}\right)$ & $\begin{array}{c}\text { Utility discount factor for } \\
\text { remanufactured products }\left(\beta_{l}\right)\end{array}$ \\
\hline Segment 1 & 3000 units & $\$ 1,000$ & 0.1 \\
Segment 2 & 4000 units & $\$ 800$ & 0.3 \\
Segment 3 & 3000 units & $\$ 600$ & 0.5 \\
\hline
\end{tabular}

Depending on the sensitivity to price and perception of the remanufactured product, consumers in the target market can be clustered into three groups $(l=3)$. Table 2 gives information on the three market segments. The sizes of the market segments are estimated to be 3,000, 4,000, and 3000 units, respectively. In the table, the critical price $\left(\bar{P}_{l}\right)$ represents the maximum price that consumers of the segment are willing to consider paying for the product. In other words, if a product is sold at a price greater than its critical value, then no customers will choose that product. Higher critical price implies that the segment is less sensitive to price change. The utility discount factor $\left(\beta_{l}\right)$ reflects the segment's perception of remanufactured products. If the discount factor is 0.1 , the utility is discounted to $10 \%$. In other words, a greater factor indicates that the segment better appreciates remanufactured products.

$$
\begin{aligned}
& u_{o, l}=u_{o, \text { perf }, l} \times u_{o, \text { price }, l} \times u_{o, \text { new }, l} \\
& \text { where } \\
& u_{o, \text { perf }, l} \in[0,1] \text { and given } \\
& u_{o, \text { price }, l}=\max \left(0,1-P_{o} / \bar{P}_{l}\right) \\
& u_{o, \text { new }, l}= \begin{cases}1 & \text { if choice } o \text { is a new product } \\
\beta_{l} & \text { else (choice } o \text { is a remanufactured product) }\end{cases} \\
& \qquad d_{n, l}\left(P_{n}, P_{r}\right)=\frac{u_{n, l}}{\sum_{o \in O} u_{o, l}} ; d_{r, l}\left(P_{n}, P_{r}\right)=\frac{u_{r, l}}{\sum_{o \in O} u_{o, l}}
\end{aligned}
$$

Equation (7) shows the multiplicative utility model applied in the case study, where $O$ is the

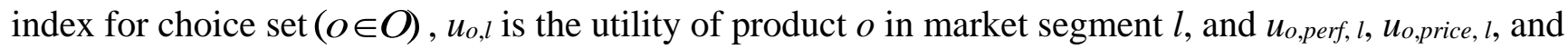


$u_{o, n e w, l}$ denote product $o$ 's utility in market segment $l$ with respect to performance, price, and newness, respectively. $P_{o}$ denotes the price of product $o$. The market share of a product is then obtained by Equation (8).

\subsection{Optimization Results}

This section presents the optimization results. The case problem was solved using Analytic Solver Platform (version 15). 'Large-Scale SQP Solver Engine' and 'OptQuest Solver Engine' were applied to find globally optimal (or near-optimal) solutions. To determine the degree of environmental-impact saving achievable with the maximum profit, the target $\delta$ for environmental-impact saving was initially set to be 0 .

Table 3 shows the optimization result for the baseline case. Production of only new products is expected to achieve a total profit of 1.14 million dollars. The optimal selling price is $\$ 528$, which is lower than that of competitor $1(\$ 800)$ but higher than those of competitors $2(\$ 500)$ and $3(\$ 400)$. The market share will be $43 \%, 45 \%$, and $29 \%$ in segments 1, 2, and 3, respectively, which corresponds to a total of 3,976 out of 10,000 units. While the new product takes the lead in segments 1 and 2 , consumers of segment 3 prefer competitor 3 which is a remanufactured product; compared to other consumers, they are more sensitive to price, less sensitive to newness.

Table 3. Optimization results for the baseline case (new product only)

\begin{tabular}{|c|c|c|c|c|c|}
\hline & & Segment 1 & Segment 2 & Segment 3 & Total \\
\hline \multirow{4}{*}{ Market share } & New product & $43 \%$ & $45 \%$ & $29 \%$ & $40 \%$ \\
\hline & Competitor 1 & $18 \%$ & $0 \%$ & $0 \%$ & $6 \%$ \\
\hline & Competitor 2 & $33 \%$ & $35 \%$ & $29 \%$ & $33 \%$ \\
\hline & Competitor 3 & $6 \%$ & $20 \%$ & $41 \%$ & $22 \%$ \\
\hline \multicolumn{2}{|l|}{ Selling price } & \multicolumn{4}{|c|}{$\$ 528$} \\
\hline \multicolumn{2}{|c|}{ Production quantity } & \multicolumn{4}{|c|}{3,976 units } \\
\hline \multicolumn{2}{|l|}{ Total cost } & \multicolumn{4}{|c|}{$\$ 964,975$} \\
\hline \multicolumn{2}{|l|}{ Total revenue } & \multicolumn{4}{|c|}{$\$ 2,101,034$} \\
\hline \multicolumn{2}{|l|}{ Total profit } & \multicolumn{4}{|c|}{$\$ 1,136,059$} \\
\hline \multicolumn{2}{|c|}{ Environmental-impact saving } & \multicolumn{4}{|c|}{$0 \mathrm{~kg} \mathrm{CO}_{2}$ equivalent } \\
\hline
\end{tabular}


Table 4. Optimization results for the target case (a line of new and remanufactured products)

\begin{tabular}{|c|c|c|c|c|c|}
\hline & & Segment 1 & Segment 2 & Segment 3 & Total \\
\hline \multirow{5}{*}{ Market share } & New product & $40 \%(-3 \%)$ & $36 \%(-9 \%)$ & $16 \%(-13 \%)$ & $31 \%(-9 \%)$ \\
\hline & Reman. product & $5 \%$ & $15 \%$ & $25 \%$ & $15 \%$ \\
\hline & Competitor 1 & $18 \%$ & $0 \%$ & $0 \%$ & $5 \%(-1 \%)$ \\
\hline & Competitor 2 & $32 \%(-1 \%)$ & $31 \%(-4 \%)$ & $25 \%(-4 \%)$ & $30 \%(-3 \%)$ \\
\hline & Competitor 3 & $5 \%(-1 \%)$ & $18 \%(-2 \%)$ & $34 \%(-7 \%)$ & $19 \%(-3 \%)$ \\
\hline \multicolumn{2}{|l|}{ Buyback price } & \multicolumn{4}{|c|}{ \$34 (Good); \$24 (Poor) } \\
\hline \multicolumn{2}{|c|}{ Takeback quantity } & \multicolumn{4}{|c|}{562 units (Good); 1,190 units (Poor) } \\
\hline \multicolumn{2}{|c|}{ Selling price } & \multicolumn{4}{|c|}{$\$ 554$ (new); $\$ 455$ (remanufactured) } \\
\hline \multicolumn{2}{|c|}{ Production quantity } & \multicolumn{4}{|c|}{3,109 units (new); 1,504 units (remanufactured) } \\
\hline \multicolumn{2}{|l|}{ Total cost } & \multicolumn{4}{|c|}{$\$ 854,515$} \\
\hline \multicolumn{2}{|l|}{ Total revenue } & \multicolumn{4}{|c|}{$\$ 2,406,967$} \\
\hline \multicolumn{2}{|l|}{ Total profit } & \multicolumn{4}{|c|}{$\$ 1,552,452$} \\
\hline \multicolumn{2}{|c|}{ Environmental-impact saving } & \multicolumn{4}{|c|}{$50,826 \mathrm{~kg} \mathrm{CO}_{2}$ equivalent } \\
\hline
\end{tabular}

Now, a question of interest is whether or not the target case can create a greater profit than the baseline case. Table 4 presents the optimization result for the target case, where both the new and remanufactured products are offered to the market. In a nutshell, including the remanufactured product is desirable. The total profit is expected to be 1.55 million dollars with the approximate market share of $46 \%$ in total (i.e., 3,109 units of new and 1,504 units of remanufactured products). Compared to the baseline case, remanufacturing enables the OEM to take approximately $6 \%$ of the market share from competitors. Looking at the results in detail by segment, the market share grows especially in segment 3 (by $12 \%$ in total), in which the consumers prefer affordable products and care less for newness.

It should be pointed out that remanufacturing does cannibalize the new product sales in this particular case. The new product loses up to $13 \%$ of its market share. Despite the cannibalization, however, remanufacturing brings a greater value and increases the total profit by 0.4 million dollars (i.e., $36.7 \%$ increase). In addition, the environmental benefit of remanufacturing seems significant.

Environmental-impact savings of approximately 51 metric tons of $\mathrm{CO}_{2}$ equivalent are expected from the entire production.

To be more specific, the optimal prices and production plan for achieving the maximum total 
profit can be summarized as follows:

- Buyback pricing: The OEM should collect 562 units of good-quality and 1,190 units of poorquality smartphones by paying $\$ 34$ and $\$ 24$ for each, respectively.

- Sales pricing: The OEM should produce 3,109 units of new and 1,504 units of remanufactured smartphones. The optimal selling prices for the new and remanufactured products are $\$ 554$ and $\$ 455$, respectively.

- Production planning: The optimal production plan starts from disassembling collected end-oflife products. A total of 562 units of good-quality and 1,190 units of poor-quality smartphones should be disassembled first. The detailed optimal plan afterwards is shown in Figure 6. Boxes in the figure represent an item and arrows to and from a box represent the flows of input and output, respectively. Taking front screen assembly as an example, the initial disassembly of smartphones retrieves 958.3 units of working and 793.7 units of non-working front screen assemblies. Nine hundred and fifty-eight working and 793 non-working units are further disassembled into digitizer, LCD screen, ear speaker, and frame; remaining units are sent to recyclers for material recovery. From disassembly of the front screen assembly, 1,259 working digitizers are harvested and pass through reconditioning operations. The others (including 491 units of non-working digitizers) proceed to material recovery. Reconditioned digitizers are used in reassembling 1,504 units of the front screen assembly. The 245 units of parts in short are purchased externally. Finally, the 1,504 units of remanufactured front screen assemblies are assembled with other parts to make 1,504 units of remanufactured smartphone. The other parts of the figure can be interpreted in a similar way.

Table 4 shows that the OEM that aims to maximize the total profit can also expect environmental-impact savings of 51 metric tons of $\mathrm{CO}_{2}$ equivalent. Suppose that the OEM wants to achieve greater environmental-impact savings, even if that might reduce the total profit. The OEM can obtain such a greener solution by increasing $\delta$ to the desired level. Table 5 shows the results of a sensitivity analysis in which $\delta$ was incrementally increased from 60 to 100 metric tons, with an increment of 10 metric tons. As $\delta$ increases, a greater amount of remanufacturing is motivated. More takeback is conducted with higher buyback prices, and a greater number of remanufactured products are produced and distributed for a lower selling price. 


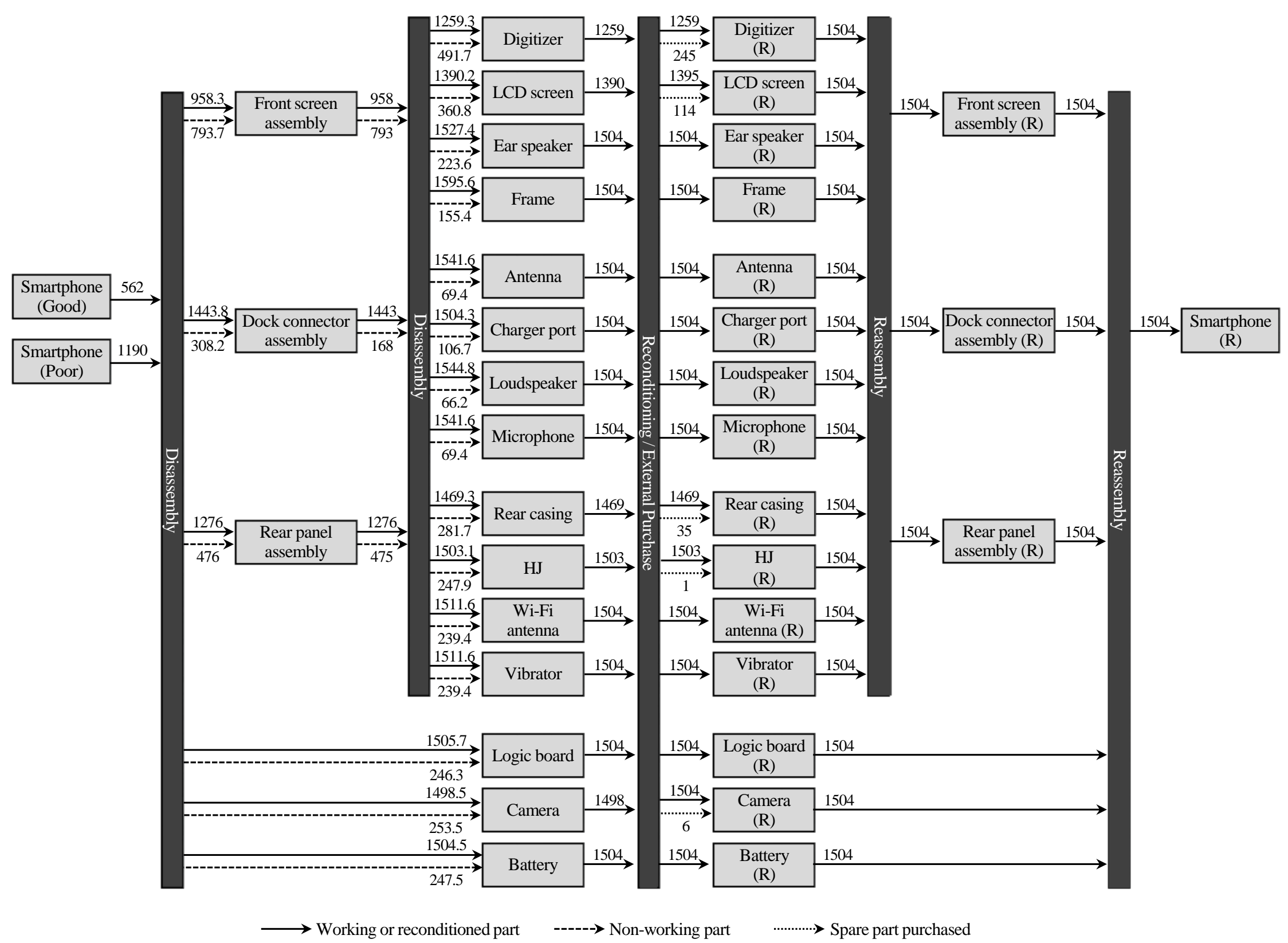

Figure 6. Graphical representation of the optimal solution 
Plotting the results in Table 5 creates an efficient frontier in Figure 7. Given the baseline case as the reference point, the points in the grey area represent green profit opportunities (i.e., opportunities for increased green profits compared to producing only new products) where the OEM can achieves greater profits as well as greater environmental-impact savings. In this case study, there exist multiple (actually an infinite number of) solutions in the grey area. This implies that the OEM has limitless potential to make a green profit, and the proposed model can help exploit this potential with an optimized line of new and remanufactured products.

Table 5. Sensitivity analysis on the target $\delta$ for minimum environmental-impact saving

\begin{tabular}{lccccc}
\hline & $\boldsymbol{\delta}=\mathbf{6 0 , 0 0 0}$ & $\boldsymbol{\delta}=\mathbf{7 0 , 0 0 0}$ & $\boldsymbol{\delta}=\mathbf{8 0 , 0 0 0}$ & $\boldsymbol{\delta}=\mathbf{9 0 , 0 0 0}$ & $\boldsymbol{\delta}=\mathbf{1 0 0 , 0 0 0}$ \\
\hline Buyback price (good) & $\$ 42$ & $\$ 49$ & $\$ 68$ & $\$ 66$ & $\$ 74$ \\
Buyback price (poor) & $\$ 28$ & $\$ 34$ & $\$ 39$ & $\$ 47$ & $\$ 53$ \\
Takeback quantity (good) & 700 units & 821 units & 1,131 units & 1,104 units & 1,239 units \\
Takeback quantity (poor) & 1,422 units & 1,709 units & 1,957 units & 2,325 units & 2,666 units \\
Selling price (new) & $\$ 561$ & $\$ 579$ & $\$ 646$ & $\$ 659$ & $\$ 684$ \\
Selling price (reman.) & $\$ 415$ & $\$ 378$ & $\$ 361$ & $\$ 306$ & $\$ 252$ \\
Production quantity (new) & 2,960 units & 2,646 units & 2,017 units & 1,899 units & 1,699 units \\
Production quantity (reman.) & 1,743 units & 2,010 units & 2,270 units & 2,540 units & 2,802 units \\
\hline (1) Cost (new) & $\$ 718,392$ & $\$ 642,184$ & $\$ 489,526$ & $\$ 460,887$ & $\$ 412,347$ \\
(2) Cost (reman.) & $\$ 127,194$ & $\$ 162,887$ & $\$ 225,242$ & $\$ 260,132$ & $\$ 320,356$ \\
(3) Total cost (=(1)+(2)) & $\$ 845,586$ & $\$ 805,071$ & $\$ 714,768$ & $\$ 721,019$ & $\$ 732,703$ \\
(4) Revenue (new) & $\$ 1,659,658$ & $\$ 1,533,140$ & $\$ 1,303,680$ & $\$ 1,251,714$ & $\$ 1,161,296$ \\
(5) Revenue (reman.) & $\$ 723,343$ & $\$ 760,497$ & $\$ 818,392$ & $\$ 776,394$ & $\$ 706,588$ \\
(6) Total revenue (=(4)+(5)) & $\$ 2,383,001$ & $\$ 2,293,637$ & $\$ 2,122,072$ & $\$ 2,028,108$ & $\$ 1,867,883$ \\
\hline Total profit (=(6)-(3)) & $\mathbf{\$ 1 , 5 3 7 , 4 1 4}$ & $\mathbf{\$ 1 , 4 8 8 , 5 6 6}$ & $\mathbf{\$ 1 , 4 0 7 , 3 0 4}$ & $\mathbf{\$ 1 , 3 0 7 , 0 8 8}$ & $\mathbf{\$ 1 , 1 3 5 , 1 8 1}$ \\
\hline
\end{tabular}

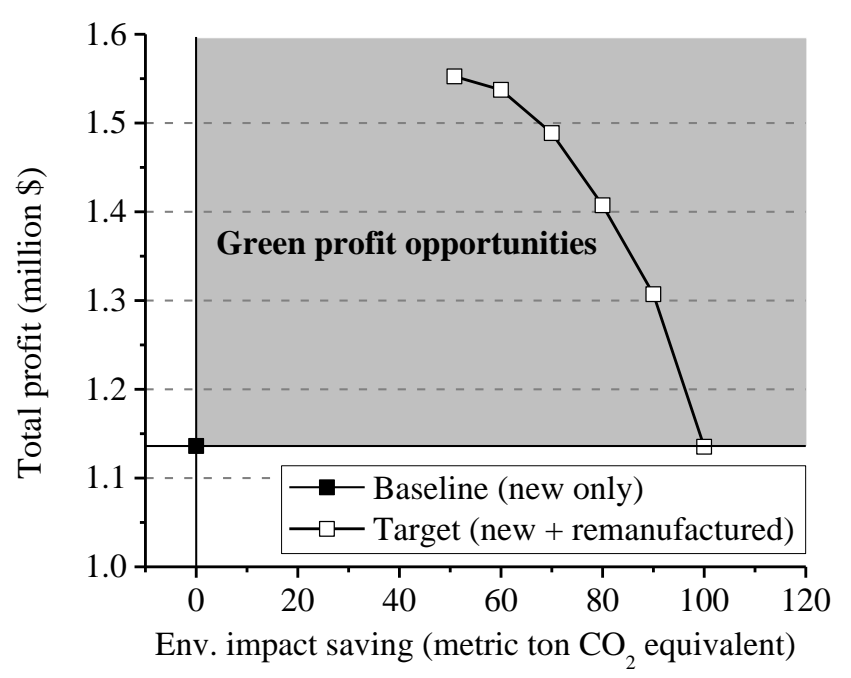

Figure 7. Pareto frontier and green profit opportunities 


\subsection{Sensitivity Analysis}

The optimization results in Section 4.2 showed that the OEM could generate green profit by offering both new and remanufactured products. The target case resulted in a greater profit as well as more environmental-impact saving than the baseline case. Since the optimization model involves many parameter values, however, one might question whether the single scenario of parameter values will be sufficient to guarantee green profit. This section conducts sensitivity analyses to determine the effects of different settings of parameter values on green profit opportunities. Additional scenarios are considered to investigate the effect of (1) consumer type, (2) operational cost, and (3) takeback regulation and available supply of end-of-life products.

Effect of consumer type. Previously, it was assumed that the target market is heterogeneous and consists of three market segments (Table 2), which represent different types of consumer in terms of their sensitivity to price and perception of the remanufactured product. To be more specific, segment 1 represents consumers who consider the newness of product to be very important and strongly prefer to purchase a new product despite its higher price. Their critical price is $\$ 1,000$, while the utility discount factor for remanufactured products (i.e., $\beta_{1}$ ) is 0.1 . This implies that the label 'remanufactured' is equivalent to a $\$ 900$ price increase for the consumers. Segment 3, on the other hand, represents consumers who are more price-sensitive. They also prefer a new product but to a lesser degree than consumers of segment 1. Considering that their critical price is $\$ 600$ and $\beta_{3}$ is 0.5 , the label 'remanufactured' has the same effect as a $\$ 300$ price increase. This implies that the consumers in segment 3 are willing to purchase a remanufactured product if the price is sufficiently (i.e., $\$ 300$ or more) lower than that of the equivalent new product. Finally, Segment 2 represents the 'average' consumers, positioned in-between Segments 1 and 3. Segment 2 is more concerned with the price than segment 1, but less so than segment 3; segment 2 cares about newness more than does segment 3 , but 
Table 6. Sensitivity analysis: the effect of consumer type

\begin{tabular}{|c|c|c|c|c|c|c|c|}
\hline & & \multicolumn{2}{|c|}{ Segment 1 only } & \multicolumn{2}{|c|}{ Segment 2 only } & \multicolumn{2}{|c|}{ Segment 3 only } \\
\hline & & Baseline & Target & Baseline & Target & Baseline & Target \\
\hline \multirow{5}{*}{ Market share } & New product & $33 \%$ & $31 \%$ & $39 \%$ & $32 \%$ & $43 \%$ & $30 \%$ \\
\hline & Reman. product & - & $4 \%$ & - & $13 \%$ & - & $22 \%$ \\
\hline & Competitor 1 & $22 \%$ & $21 \%$ & $0 \%$ & $0 \%$ & $0 \%$ & $0 \%$ \\
\hline & Competitor 2 & $39 \%$ & $38 \%$ & $39 \%$ & $35 \%$ & $24 \%$ & $20 \%$ \\
\hline & Competitor 3 & $7 \%$ & $6 \%$ & $22 \%$ & $20 \%$ & $33 \%$ & $28 \%$ \\
\hline \multicolumn{2}{|c|}{ Buyback price (good) } & - & $\$ 11$ & - & $\$ 31$ & - & $\$ 49$ \\
\hline \multicolumn{2}{|c|}{ Buyback price (poor) } & - & $\$ 6$ & - & $\$ 21$ & - & $\$ 36$ \\
\hline \multicolumn{2}{|c|}{ Takeback quantity (good) } & - & 178 units & - & 515 units & - & 812 units \\
\hline \multicolumn{2}{|c|}{ Takeback quantity (poor) } & - & 323 units & - & 1,065 units & - & 1,773 units \\
\hline \multicolumn{2}{|c|}{ Selling price (new) } & $\$ 696$ & $\$ 704$ & $\$ 588$ & $\$ 609$ & $\$ 470$ & $\$ 494$ \\
\hline \multicolumn{2}{|c|}{ Selling price (reman.) } & - & $\$ 618$ & - & $\$ 532$ & - & $\$ 442$ \\
\hline \multicolumn{2}{|c|}{ Production quantity (new) } & 3,299 units & 3,111 units & 3,877 units & 3,158 units & 4,306 units & 2,976 units \\
\hline \multicolumn{2}{|c|}{ Production quantity (reman.) } & - & 402 units & - & 1,328 units & - & 2,217 units \\
\hline \multicolumn{2}{|c|}{ (1) Cost (new) } & $\$ 800,667$ & $\$ 755,040$ & $\$ 940,948$ & $\$ 766,447$ & $\$ 1,045,066$ & $\$ 722,275$ \\
\hline \multicolumn{2}{|c|}{ (2) Cost (reman.) } & - & $\$ 16,773$ & - & $\$ 83,310$ & - & $\$ 180,570$ \\
\hline \multicolumn{2}{|c|}{ (3) Total cost $(=(1)+(2))$} & $\$ 800,667$ & $\$ 771,813$ & $\$ 940,948$ & $\$ 849,756$ & $\$ 1,045,066$ & $\$ 902,845$ \\
\hline \multicolumn{2}{|c|}{ (4) Revenue (new) } & $\$ 2,296,670$ & $\$ 2,190,250$ & $\$ 2,280,974$ & $\$ 1,921,790$ & $\$ 2,025,369$ & $\$ 1,469,754$ \\
\hline \multicolumn{2}{|c|}{ (5) Revenue (reman.) } & - & $\$ 248,258$ & - & $\$ 706,010$ & - & $\$ 979,633$ \\
\hline \multicolumn{2}{|c|}{ (6) Total revenue $(=(4)+(5))$} & $\$ 2,296,670$ & $\$ 2,438,507$ & $\$ 2,280,974$ & $\$ 2,627,800$ & $\$ 2,025,369$ & $\$ 2,449,388$ \\
\hline \multicolumn{2}{|c|}{ Total profit $(=(6)-(3))$} & $\$ 1,496,003$ & $\$ 1,666,694$ & $\$ 1,340,026$ & $\$ 1,778,043$ & $\$ 980,303$ & $\$ 1,545,643$ \\
\hline \multicolumn{2}{|c|}{ Environmental-impact saving } & 0 kg & $13,996 \mathrm{~kg}$ & 0 kg & $45,324 \mathrm{~kg}$ & 0 kg & $74,808 \mathrm{~kg}$ \\
\hline \multicolumn{2}{|c|}{ Increase in green profit } & \multicolumn{2}{|c|}{$\$ 170,691(11.4 \%)$} & \multicolumn{2}{|c|}{$\$ 438.017(32.7 \%)$} & \multicolumn{2}{|c|}{$\$ 565,340(57.7 \%)$} \\
\hline
\end{tabular}

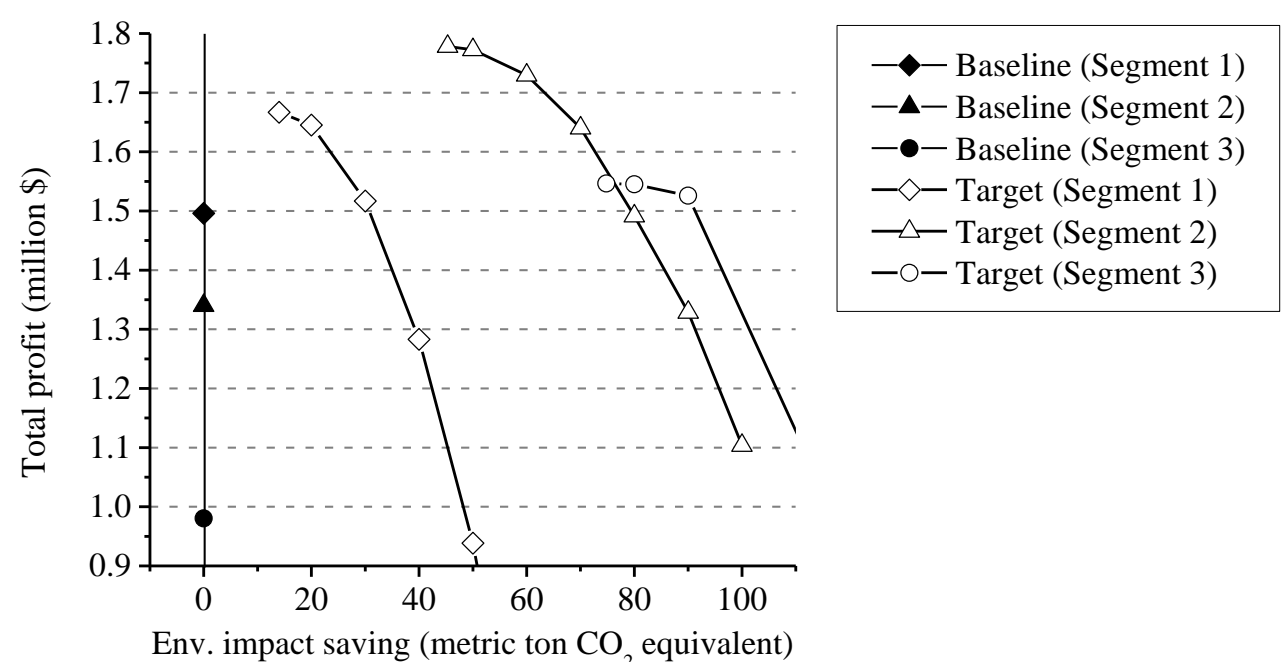

Figure 8. Change in green profit opportunities: the effect of consumer type

less so than segment 1.

In Sec. 4.2, the optimization model showed that offering a line of new and remanufactured products has multiple green profit opportunities in the target market. In such a heterogeneous market 
that consists of all three segments, this is not a surprising result as segment 3 creates a significant demand for the remanufactured products (Table 4). The result, however, raises the question of whether such green profit opportunities will exist in a market with a different consumer composition. For instance, what if the relative size of segment 1 increases? What about the case of a homogeneous market that consists of solely the consumers in segment 1 ? To examine the effect of consumer type on green profit opportunities, this section tests three additional scenarios, each of which assumes a homogeneous market of a particular segment (market size is 10,000 units in all three cases).

Table 6 shows the analysis results (the optimal solutions for maximum profit). The results demonstrate that the target case outperforms the baseline case in all three markets, although the level of increase in green profit differs among the consumer types. As expected, the greatest increase is observed in the 'Segment 3 only' market. A 58\% profit increase is expected, together with environmental-impact savings of $\sim 75$ metric tons of $\mathrm{CO}_{2}$ equivalent. Since the consumers have the lowest critical price and the highest utility discount factor (Table 2), the market provides a remanufacturing-friendly environment, and more takeback and remanufacturing are recommended compared to the other two cases. Not as much as the 'Segment 3 only' market, but the other two markets also show significant increases in green profit. Even in the 'Segment 1 only' market, an $11 \%$ profit increase is expected, together with environmental-impact savings of $\sim 14$ metric tons of $\mathrm{CO}_{2}$ equivalent.

Figure 8 compares the Pareto frontiers of the three scenarios. For each scenario, the $\delta$ value was increased to 100 metric tons in 10-metric-ton increments. Given the baseline result of each scenario (Table 6) as the reference, the points on the frontiers above the reference represent the opportunities for the OEM to achieve a green profit. The results show that multiple green profit opportunities exist in all three scenarios.

Regardless of consumer type, the optimization results indicate that offering both new and 
remanufactured products is better than producing only new products, in terms of both profit and environmental-impact saving. This implies the potential for green profits in a market comprising any combination of consumer types, and the OEM can exploit this potential with a well-designed product line comprising both new and remanufactured products.

Effect of operational cost. One advantage of remanufacturing is that it can reduce material costs by reducing new part purchases. The advantage is increased if the product consists of high-cost parts. However, remanufacturing requires additional operations, such as disassembly, part reconditioning, and reassembly. Depending on the product nature (e.g., disassembly structure, ease of disassembly and ease of reconditioning) and production environment (e.g., factory location, productivity of the factory and labor cost), such operations may increase costs, reducing the overall cost advantage.

The OEM could generate green profit in the previous scenario (where the material and operational costs were assumed as Tables A2 and A3 in the Appendix), but what if there is a massive increase in the operational costs? Will there be any green profit opportunities in such a case? To investigate the effect of operational costs on green profit opportunities, two additional scenarios were tested, in which higher operational costs (i.e., $200 \%$ and $400 \%$ of the original costs) were assumed.

Table 7 and Figure 9 show the analysis results. As expected, the greater the operational costs, the lower the maximum profit. The environmental-impact saving also decreases as the amount of takeback and remanufacturing is reduced. Of more interest here is the gap between the baseline and target cases. The gap decreases as operational costs increase, which implies reduced green profit opportunities. However, multiple opportunities exist in all scenarios. In this particular case study, the negative effect of high operational costs seems marginal. In the original scenario (100\% cost), the gap was reported to be $36.7 \%$. Despite $400 \%$ costs, the gap is affected only slightly, decreasing to $36.3 \%$. 
Table 7. Sensitivity analysis: the effect of operational costs

\begin{tabular}{|c|c|c|c|c|c|c|c|}
\hline & & \multicolumn{2}{|c|}{$100 \%$ costs* } & \multicolumn{2}{|c|}{$200 \%$ costs } & \multicolumn{2}{|c|}{$400 \%$ costs } \\
\hline & & Baseline & Target & Baseline & Target & Baseline & Target \\
\hline \multirow{5}{*}{ Market share } & New product & $39.8 \%$ & $31.1 \%$ & $39.0 \%$ & $30.7 \%$ & $37.5 \%$ & $29.9 \%$ \\
\hline & Reman. product & - & $15.0 \%$ & - & $14.8 \%$ & - & $13.8 \%$ \\
\hline & Competitor 1 & $5.5 \%$ & $5.4 \%$ & $5.5 \%$ & $5.4 \%$ & $5.6 \%$ & $5.4 \%$ \\
\hline & Competitor 2 & $32.8 \%$ & $29.5 \%$ & $33.2 \%$ & $29.8 \%$ & $33.9 \%$ & $30.7 \%$ \\
\hline & Competitor 3 & $21.9 \%$ & $19.0 \%$ & $22.3 \%$ & $19.3 \%$ & $23.0 \%$ & $20.2 \%$ \\
\hline \multicolumn{2}{|c|}{ Buyback price (good) } & - & $\$ 34$ & - & $\$ 34$ & - & $\$ 31$ \\
\hline \multicolumn{2}{|c|}{ Buyback price (poor) } & - & $\$ 24$ & - & $\$ 23$ & - & $\$ 22$ \\
\hline \multicolumn{2}{|c|}{ Takeback quantity (good) } & - & 562 units & - & 560 units & - & 520 units \\
\hline \multicolumn{2}{|c|}{ Takeback quantity (poor) } & - & 1,190 units & - & 1,160 units & - & 1,089 units \\
\hline \multicolumn{2}{|c|}{ Selling price (new) } & $\$ 528$ & $\$ 554$ & $\$ 534$ & $\$ 558$ & $\$ 544$ & $\$ 565$ \\
\hline \multicolumn{2}{|c|}{ Selling price (reman.) } & - & $\$ 455$ & - & $\$ 462$ & - & $\$ 482$ \\
\hline \multicolumn{2}{|c|}{ Production quantity (new) } & 3,976 units & 3,109 units & 3,902 units & 3,067 units & 3,745 units & 2,989 units \\
\hline \multicolumn{2}{|c|}{ Production quantity (reman.) } & - & 1,504 units & - & 1,478 units & - & 1,381 units \\
\hline \multicolumn{2}{|l|}{ (1) Cost (new) } & $\$ 964,975$ & $\$ 754,554$ & $\$ 1,059,239$ & $\$ 804,167$ & $\$ 1,127,994$ & $\$ 900,287$ \\
\hline \multicolumn{2}{|c|}{ (2) Cost (reman.) } & - & $\$ 99,960$ & - & $\$ 142,555$ & - & $\$ 215,112$ \\
\hline \multicolumn{2}{|c|}{ (3) Total cost $(=(1)+(2))$} & $\$ 964,975$ & $\$ 854,515$ & $\$ 1,059,239$ & $\$ 946,723$ & $\$ 1,127,994$ & $\$ 1,115,399$ \\
\hline \multicolumn{2}{|c|}{ (4) Revenue (new) } & $\$ 2,101,034$ & $\$ 1,723,008$ & $\$ 2,082,343$ & $\$ 1,711,056$ & $\$ 2,038,060$ & $\$ 1,689,421$ \\
\hline \multicolumn{2}{|c|}{ (5) Revenue (reman.) } & - & $\$ 683,959$ & - & $\$ 682,342$ & - & $\$ 665,968$ \\
\hline \multicolumn{2}{|c|}{ (6) Total revenue $(=(4)+(5))$} & $\$ 2,101,034$ & $\$ 2,406,967$ & $\$ 2,082,343$ & $\$ 2,393,398$ & $\$ 2,038,060$ & $\$ 2,355,389$ \\
\hline \multicolumn{2}{|c|}{ Total profit $(=(6)-(3))$} & $\$ 1,136,059$ & $\$ 1,552,452$ & $\$ 1,059,239$ & $\$ 1,446,675$ & $\$ 910,066$ & $\$ 1,239,990$ \\
\hline \multicolumn{2}{|c|}{ Environmental-impact saving } & 0 kg & $50,826 \mathrm{~kg}$ & 0 kg & $49,958 \mathrm{~kg}$ & 0 kg & $46,513 \mathrm{~kg}$ \\
\hline \multicolumn{2}{|c|}{ Increase in green profit } & \multicolumn{2}{|c|}{$\$ 416,393(36.7 \%)$} & \multicolumn{2}{|c|}{$\$ 387,436(36.6 \%)$} & \multicolumn{2}{|c|}{$\$ 329,924(36.3 \%)$} \\
\hline
\end{tabular}

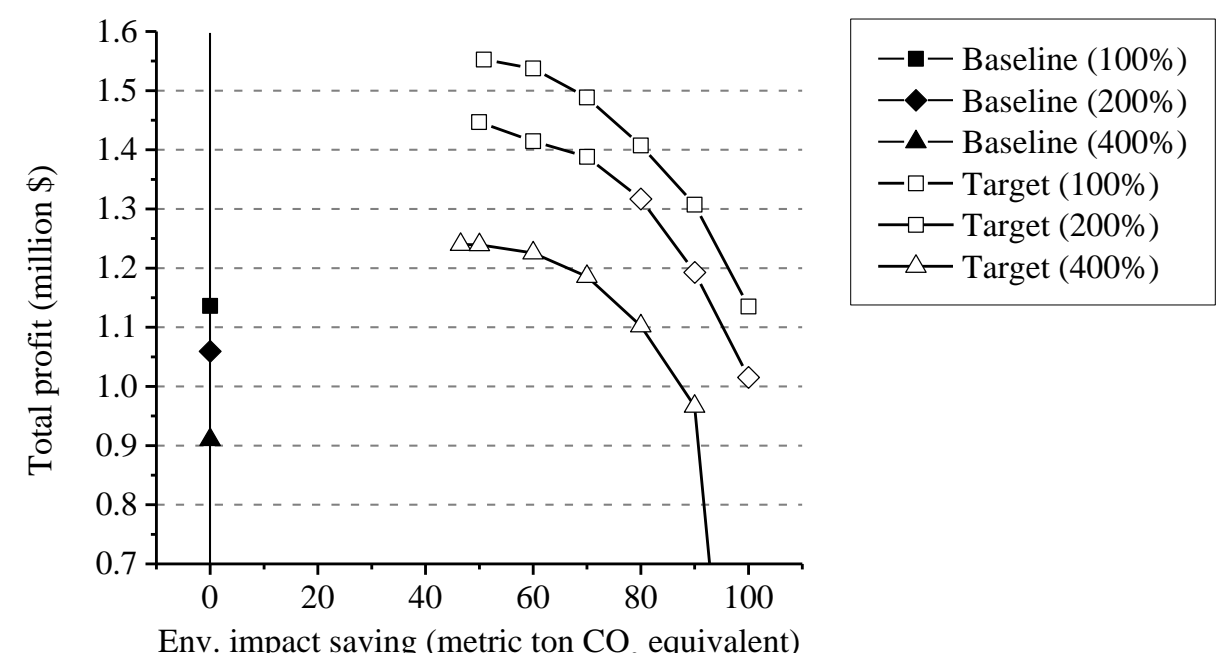

Figure 9. Change in green profit opportunities: the effect of operational costs

Operational costs are highly variable even for the same products, and so consideration of a single scenario of operational costs may not guarantee green profit. The results in Table 7 and Figure 9 
help address this concern. They show that the green profit opportunities will sustain the increased operational costs, and offering a line of new and remanufactured products will be more profitable and greener than producing new products only, irrespective of the change in costs.

Effect of takeback regulation and available supply of end-of-life products. The final sensitivity analysis considers the effect of waste-treatment environmental legislation, such as the Waste Electrical and Electronic Equipment Directive (WEEE) and the Extended Producer Responsibility (EPR).

Environmental legislation requires that manufacturers take back a certain weight of end-of-life products so that the total weight collected exceeds a mandatory minimum-weight target. Proper treatment should follow mainly either reuse (including remanufacturing) or recycling. Here, suppose that there is a takeback regulation enforcing takeback of $80 \%$ of total available end-of-life products. Even if the OEM produces only new products (i.e., baseline), takeback is conducted and all collected units are recycled

Table 8. Sensitivity analysis: the effect of takeback regulation and available supply

\begin{tabular}{|c|c|c|c|c|c|c|c|}
\hline & \multicolumn{2}{|c|}{ 100\% supply } & \multicolumn{2}{|c|}{ 50\% supply } & \multicolumn{2}{|c|}{$\underline{20 \%}$ supply } \\
\hline & & Baseline & Target & Baseline & Target & Baseline & Target \\
\hline \multirow{5}{*}{ Market share } & New product & $40 \%$ & $30 \%$ & $40 \%$ & $30 \%$ & $40 \%$ & $34 \%$ \\
\hline & Reman. product & - & $17 \%$ & - & $17 \%$ & - & $12 \%$ \\
\hline & Competitor 1 & $6 \%$ & $5 \%$ & $6 \%$ & $5 \%$ & $6 \%$ & $5 \%$ \\
\hline & Competitor 2 & $33 \%$ & $29 \%$ & $33 \%$ & $29 \%$ & $33 \%$ & $30 \%$ \\
\hline & Competitor 3 & $22 \%$ & $19 \%$ & $22 \%$ & $19 \%$ & $22 \%$ & $19 \%$ \\
\hline \multicolumn{2}{|c|}{ Buyback price (good) } & - & $\$ 97$ & - & $\$ 97$ & - & $\$ 114$ \\
\hline \multicolumn{2}{|c|}{ Buyback price (poor) } & - & $\$ 96$ & - & $\$ 96$ & - & $\$ 90$ \\
\hline \multicolumn{2}{|c|}{ Takeback quantity (good) } & - & 1,609 units & - & 806 units & - & 379 units \\
\hline \multicolumn{2}{|c|}{ Takeback quantity (poor) } & - & 4,791 units & - & 2,394 units & - & 901 units \\
\hline \multicolumn{2}{|c|}{ Selling price (new) } & $\$ 528$ & $\$ 562$ & $\$ 528$ & $\$ 562$ & $\$ 528$ & $\$ 542$ \\
\hline \multicolumn{2}{|c|}{ Selling price (reman.) } & - & $\$ 430$ & - & $\$ 429$ & - & $\$ 503$ \\
\hline \multicolumn{2}{|c|}{ Production quantity (new) } & 3,976 units & 2,968 units & 3,976 units & 2,962 units & 3,976 units & 3,360 units \\
\hline \multicolumn{2}{|c|}{ Production quantity (reman.) } & - & 1,669 units & - & 1,676 units & - & 1,178 units \\
\hline \multicolumn{2}{|l|}{ (1) Cost (new) } & $\$ 1,574,652$ & $\$ 720,334$ & $\$ 1,269,814$ & $\$ 718,877$ & $\$ 1,014,123$ & $\$ 815,472$ \\
\hline \multicolumn{2}{|c|}{ (2) Cost (reman.) } & - & $\$ 661,488$ & - & $\$ 357,971$ & - & $\$ 181,620$ \\
\hline \multicolumn{2}{|c|}{ (3) Total cost $(=(1)+(2))$} & $\$ 1,574,652$ & $\$ 1,381,822$ & $\$ 1,269,814$ & $\$ 1,076,848$ & $\$ 1,014,123$ & $\$ 997,092$ \\
\hline \multicolumn{2}{|c|}{ (4) Revenue (new) } & $\$ 2,101,034$ & $\$ 1,666,702$ & $\$ 2,101,034$ & $\$ 1,664,270$ & $\$ 2,101,034$ & $\$ 1,821,760$ \\
\hline \multicolumn{2}{|c|}{ (5) Revenue (reman.) } & - & $\$ 717,314$ & - & $\$ 718,526$ & - & $\$ 592,845$ \\
\hline \multicolumn{2}{|c|}{ (6) Total revenue $(=(4)+(5))$} & $\$ 2,101,034$ & $\$ 2,384,017$ & $\$ 2,101,034$ & $\$ 2,382,796$ & $\$ 2,101,034$ & $\$ 2,414,605$ \\
\hline \multicolumn{2}{|c|}{ Total profit $(=(6)-(3))$} & $\$ 526,382$ & $\$ 1,002,195$ & $\$ 831,220$ & $\$ 1,305,948$ & $\$ 1,014,123$ & $\$ 1,417,513$ \\
\hline \multicolumn{2}{|c|}{ Environmental-impact saving } & $23,360 \mathrm{~kg}$ & $75,064 \mathrm{~kg}$ & $11,680 \mathrm{~kg}$ & $63,020 \mathrm{~kg}$ & $4,672 \mathrm{~kg}$ & $37,146 \mathrm{~kg}$ \\
\hline \multicolumn{2}{|c|}{ Increase in green profit } & \multicolumn{2}{|c|}{$\$ 475,813(90.4 \%)$} & \multicolumn{2}{|c|}{$\$ 474,728(57.1 \%)$} & \multicolumn{2}{|c|}{$\$ 403,390(39.8 \%)$} \\
\hline
\end{tabular}


for material recovery. Thus the company achieves some environmental-impact savings by reducing the amount of waste landfilled or incinerated.

Since the takeback target depends on the amount of available end-of-life products, a greater quantity of end-of-life products implies a more difficult (higher) target. To assess the effect of regulation according to availability of end-of-life products, a sensitivity analysis assuming three different levels of supply availability was conducted: $100 \%$ (i.e., $A_{1}=3,000, A_{2}=5,000$ ), $50 \%$ (i.e., $A_{1}=1,500, A_{2}=2,500$ ) and $20 \%$ (i.e., $A_{1}=600, A_{2}=1,000$ ). The response function in Figure 4 was applied in all cases. This means that the ' $50 \%$ ' and ' $20 \%$ ' cases should pay two- and five-fold the original buyback prices (of the $100 \%$ case), respectively, to collect the same amount of end-of-life product.

Table 8 shows the optimization results. The results demonstrate that remanufacturing can be an effective strategy to comply with the takeback regulation. By including remanufactured products in the product portfolio (i.e., target case), the OEM can not only meet the takeback target but also increase their green profit. The benefit of remanufacturing increases according to the amount of available end-oflife products. When $100 \%$ availability is assumed, an increase in green profit more than $90 \%$ is expected.

\section{Conclusion}

The potential of generating green profits through remanufacturing needs to be supported by optimal pricing and production planning. An important fact overlooked in most previous studies is that pricing and production planning are interdependent. To achieve maximum green profits, pricing and production planning should be addressed in an integrated manner.

This article presented a new model for integrated pricing and production planning. The model is developed for OEMs who produce a line of new and remanufactured products. An advanced version of 
the transition matrix is introduced as a means to coordinate pricing with production planning, reflecting product design. The proposed model conducts buyback pricing, sales pricing, and production planning simultaneously and provides detailed solutions for achieving green profits. The solutions address potential concerns and barriers to OEM remanufacturing, which include unproven economic profitability and the environmental sustainability of remanufacturing, imbalance between the supply of end-of-life products and demand for remanufactured products, and the risk of cannibalizing new product sales.

The proposed model can help OEM remanufacturers make better decisions in their business and identify opportunities for green profits. The case study using the smartphone example demonstrated that both economic profit and environmental-impact saving can be increased simultaneously with the help of the model. Sensitivity analyses illustrated that different parameter values may increase or decrease such opportunities for green profit, but some opportunities should always be available. This does not mean that green profit opportunities always exist in all business cases. However, if any opportunities exist, the proposed model can reveal them effectively.

The proposed model assumed that product design is predefined and fixed. It also assumed that end-of-life products and remanufactured products have the same design, and no upgrade is considered in remanufacturing. In the future, a model should be developed to incorporate potential changes in product design and to further optimize product design. The current model is also developed for a single period, and the influence of the past decisions as well as the potential implication of current decisions on future periods were not considered. Fixed cost was also excluded from the consideration. Future work should involve relaxing the assumptions and extending the model to multi-period modeling.

Finding appropriate response functions and demand models was beyond the scope of this work, but it cannot be more important for the success of the proposed model. More research should be 
conducted to clarify how the market responds to the pricing decisions. Finally, the current model did not consider the case in which the competing products change their price and/or design in response to the OEM's optimal decisions. Game theory can be utilized in future to better simulate competition among firms.

\section{Acknowledgments}

This material is based upon the work at the University of Illinois supported by the National Science Foundation under Award No. 0953021. Any opinions, findings, and conclusions or recommendations expressed in this publication are those of the authors and do not necessarily reflect the views of the National Science Foundation. 


\section{Appendix A}

See Tables A1 through A3.

Table A1. Transition matrix of the smartphone

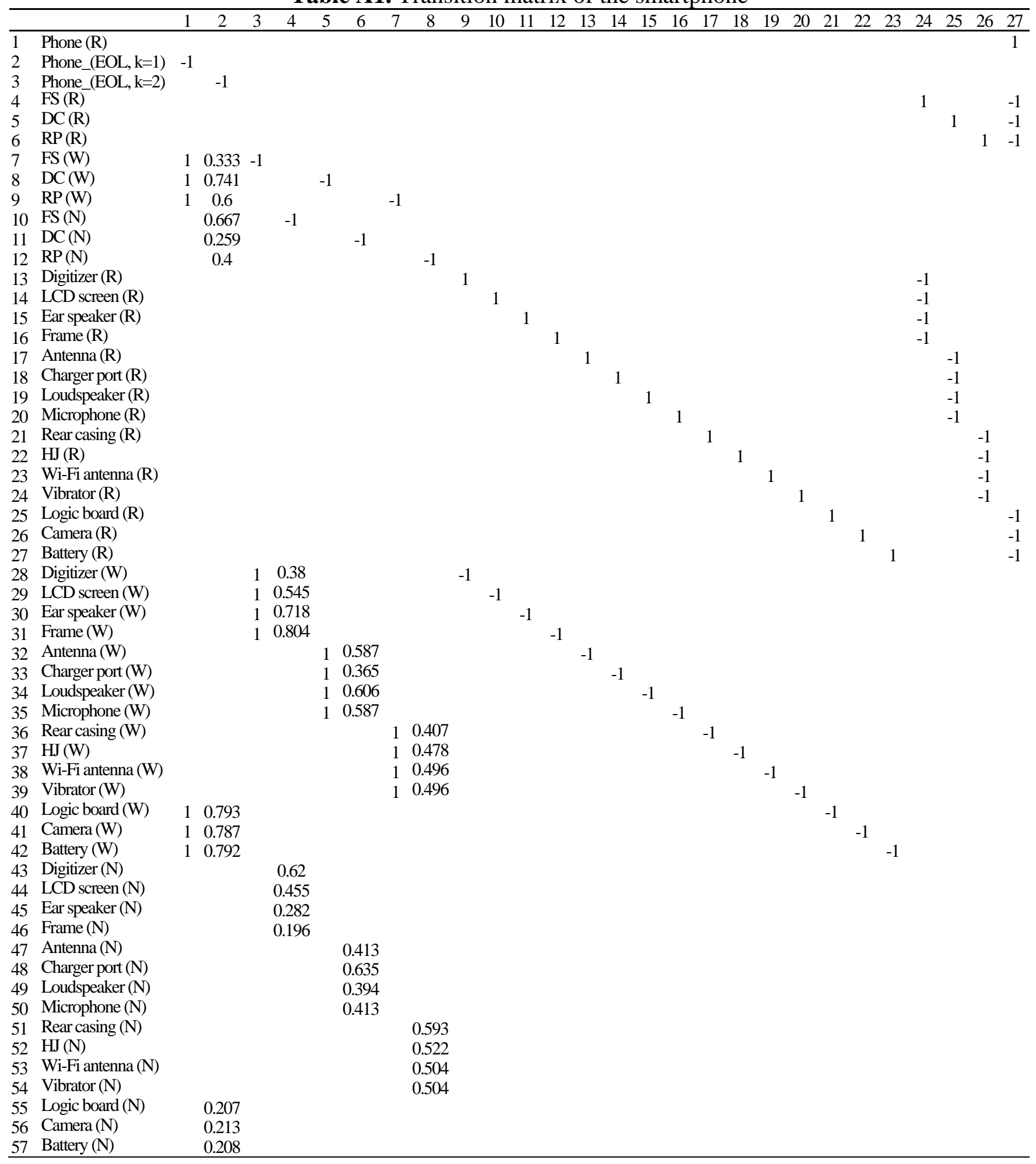


Table A2. Cost and impact parameters regarding part procurement and material recovery

\begin{tabular}{lcccc}
\hline & \multicolumn{2}{c}{ New part procurement } & \multicolumn{2}{c}{ Material recovery } \\
Impact $\left(\mathrm{kgCO}_{2}\right.$ & Cost $(\$)$ & $\begin{array}{c}\text { Impact (kg CO } 2 \\
\text { equivalent) }\end{array}$ \\
\hline Smartphone & N/A & N/A & -0.74 & 0.55 \\
FS & N/A & N/A & -0.24 & 0.11 \\
DC & N/A & N/A & -0.07 & 0.03 \\
RP & N/A & N/A & -0.17 & 0.08 \\
Digitizer & 14 & 4.75 & -0.10 & 0.04 \\
LCD screen & 22 & 4.75 & -0.10 & 0.04 \\
Ear speaker & 4 & 1.19 & -0.02 & 0.01 \\
Frame & 12 & 1.19 & -0.02 & 0.01 \\
Antenna & 4 & 0.47 & -0.01 & 0.00 \\
Charger port & 6 & 1.19 & -0.02 & 0.01 \\
Loudspeaker & 4 & 1.19 & -0.02 & 0.01 \\
Microphone & 3.6 & 0.47 & -0.01 & 0.00 \\
Rear casing & 30 & 4.75 & -0.10 & 0.04 \\
HJ & 5.6 & 1.19 & -0.02 & 0.01 \\
Wi-Fi antenna & 4 & 1.19 & -0.02 & 0.01 \\
Vibrator & 4 & 1.19 & -0.02 & 0.01 \\
Logic board & 100 & 5.59 & -0.23 & 0.05 \\
Camera & 4 & 1.24 & -0.03 & 0.01 \\
Battery & 6 & 6.18 & -0.08 & 0.06 \\
\hline
\end{tabular}

Table A3. Operational cost and environmental impact

\begin{tabular}{|c|c|c|}
\hline Operation & Cost $(\$)$ & $\begin{array}{c}\text { Impact ( } \mathrm{kg} \mathrm{CO}_{2} \\
\text { equivalent) }\end{array}$ \\
\hline 1 & 1.5 & 0.05 \\
\hline 2 & 1.5 & 0.05 \\
\hline 3 & 0.5 & 1.19 \\
\hline 4 & 0.5 & 1.19 \\
\hline 5 & 0.5 & 0.33 \\
\hline 6 & 0.5 & 0.33 \\
\hline 7 & 0.5 & 0.83 \\
\hline 8 & 0.5 & 0.83 \\
\hline 9 & 0.8 & 0.47 \\
\hline 10 & 0.5 & 0.47 \\
\hline 11 & 0.5 & 0.12 \\
\hline 12 & 0.5 & 0.12 \\
\hline 13 & 0.5 & 0.05 \\
\hline 14 & 0.5 & 0.12 \\
\hline 15 & 0.5 & 0.12 \\
\hline 16 & 0.5 & 0.05 \\
\hline 17 & 0.5 & 0.47 \\
\hline 18 & 0.5 & 0.12 \\
\hline 19 & 0.5 & 0.12 \\
\hline 20 & 0.5 & 0.12 \\
\hline 21 & 0.5 & 0.56 \\
\hline 22 & 0.5 & 0.12 \\
\hline 23 & 0.5 & 0.62 \\
\hline 24 & 1.5 & 1.19 \\
\hline 25 & 1.5 & 0.33 \\
\hline 26 & 1.5 & 0.83 \\
\hline 27 & 2 & 0.01 \\
\hline Marketing \& distribution & 13 & 0.04 \\
\hline
\end{tabular}




\section{References}

Apple Inc., 2009. Product Environmental Reports. Retrieved from http://www.apple.com/environment/reports/

Atasu, A., Guide, D.R., Wassenhove, L.N.V., 2010. So what if remanufacturing cannibalizes my new product sales? California Management Review, 52 (2).

Atasu, A., Sarvary, M., \& Wassenhove, L. N. V., 2008. Remanufacturing as a Marketing Strategy. Management Science, 54 (10), 1731-1746.

Aydin, R., Kwong, C.K., Ji, P., 2015a. Coordination of the closed-loop supply chain for product line design with consideration of remanufactured products. Journal of Cleaner Production.

Aydin, R., Kwong, C.K., Ji, P., 2015b. A novel methodology for simultaneous consideration of remanufactured and new products in product line design. International Journal of Production Economics, 169, 127-140.

Behdad, S., Kwak, M., Kim, H., Thurston, D., 2010. Simultaneous Selective Disassembly and End-of-Life Decision Making for Multiple Products That Share Disassembly Operations. Journal of Mechanical Design, 132 (4).

Ben-Akiva, M., Lerman, S., 1985. Discrete Choice Analysis: Theory and Application to Travel Demand, The MIT Press, Cambridge, Massachusetts.

Ferguson, M.E., Toktay, L.B., 2006. The Effect of Competition on Recovery Strategies. Production \& Operations Management, 15 (3), 351-368.

Fleischmann, M., Bloemhof-Ruwaard, J.M., Dekker, R., van der Laan, E., van Nunen, J., VanWassenhove, L.N., 1997. Quantitative models for reverse logistics: A review. European Journal of Operational Research, 103 (1), 1-17.

Franke, C., Basdere, B., Ciupek, M., Seliger, S., 2006. Remanufacturing of Mobile Phones - Capacity, Program and Facility Adaptation Planning. Omega, 34 (6), 562-570.

Geyer, R., Jackson, T., 2004. Supply Loops and Their Constraints: The Industrial Ecology of Recycling and Reuse. California Management Review, 46 (2), 55-73.

Goedkoop, M., Spriensma, S., 2000. The Eco-Indicator 99: A Damage Oriented Method for Life Cycle Impact Assessment.

Green, P.E., Krieger, A.M., Wind, Y., 2001. Thirty Years of Conjoint Analysis: Reflections and Prospects. Interfaces, 31 (3), S56-S73.

Guide, V.D.R., Li, J., 2010. The Potential for Cannibalization of New Products Sales by Remanufactured Products. Decision Sciences, 41 (3), 547-572.

Guide, V.D.R., Teunter, R.H., Van Wassenhove, L.N., 2003. Matching Demand and Supply to Maximize Profits from Remanufacturing. Manufacturing and Service Operations Management, 5 (4), 303-316.

Guide, V.D.R., Van Wassenhove, L.N., 2001. Managing product returns for remanufacturing. Production and Operations Management, 10 (2), 142-155.

Guide, V.D.R., Van Wassenhove, L.N., 2009. OR FORUM---The Evolution of Closed-Loop Supply Chain Research. Oper. Res., 57 (1), 10-18.

Hatcher, G.D., Ijomah, W.L., Windmill, J.F.C., 2011. Design for Remanufacture: A Literature Review and Future Research Needs, 19 (17-18), 2004-2014.

Ijomah, W.L., 2002. Model-Based Definition of the Generic Remanufacturing Business Process. The University of Plymouth.

Imtanavanich, P., Gupta, S.M., 2005. Multi-Criteria Decision Making Approach in Multiple Periods for a Disassembly-ToOrder System Under Product's Deterioration and Stochastic Yields. Proceedings of the SPIE international conference on environmentally conscious manufacturing V, Boston, MA.

Inderfurth, K., Langella, I.M., 2008. Planning Disassembly for Remanufacture-To-Order Systems. In S.M. Gupta and A.J. Lamber, eds. Environment conscious manufacturing. Boca Raton, FL: CRC Press, 387-411.

Jayaraman, V., 2006. Production planning for closed-loop supply chains with product recovery and reuse: An analytical approach. International Journal of Production Research, 44 (5), 981-998.

Kang, C.M., Hong, Y.S., 2012. Dynamic disassembly planning for remanufacturing of multiple types of products. International Journal of Production Research, 50 (22), 6236-6248.

Kang, C.M., Kwak, M.J., Cho, N.W., Hong, Y.S., 2010. Automatic derivation of transition matrix for end-of-life decision making. International Journal of Production Research, 48 (11), 3269-3298.

Kenné, J.-P., Dejax, P., Gharbi, A., 2012. Production Planning of a Hybrid Manufacturing-Remanufacturing System Under Uncertainty Within a Closed-Loop Supply Chain, 135 (1), 81-93.

Klausner, M., Hendrickson, C.T., 2000. Reverse-logistics strategy for product take-back. Interfaces, 30 (3), 156-165.

Krikke, H. R., Van Harten, A., Schuur, P.C., 1998. On a Medium Term Product Recovery and Disposal Strategy for Durable Assembly Products. International Journal of Production Research, 36 (1), 111-139.

Kwak, M., 2012. Green profit design for lifecycle. University of Illinois at Urbana-Champaign.

Kwak, M., 2015. Integrated Pricing and Production Planning for Remanufacturing. ICIC Express Letters, Part B: Applications (Accepted and in press). 
Kwak, M., Behdad, S., Zhao, Y., Kim, H.M., Thurston, D., 2011. E-waste Stream Analysis and Design Implications. Journal of Mechanical Design, 133 (10), 101003.

Kwak, M., Kim, H., 2010. Evaluating End-of-Life Recovery Profit by a Simultaneous Consideration of Product Design and Recovery Network Design. Journal of Mechanical Design, 132 (7), 071001.

Kwak, M., Kim, H., 2013. Market Positioning of Remanufactured Products with Optimal Planning for Part Upgrades. Journal of Mechanical Design, 135 (1), 011007-011007.

Kwak, M., Kim, H., 2015. Design for life-cycle profit with simultaneous consideration of initial manufacturing and end-oflife remanufacturing. Engineering Optimization, 47 (1), 18-35.

Kwak, M., Kim, H. M., 2011. Assessing product family design from an end-of-life perspective. Engineering Optimization, 43 (3), 233-255.

Kwak, M., Kim, H., Thurston, D., 2012. Formulating Second-Hand Market Value as a Function of Product Specifications, Age, and Conditions. Journal of Mechanical Design, 134 (3), 032001-032001-11.

Kwak, M., Koritz, K., Kim, H.M., 2013. Green Profit Maximization Through Joint Pricing and Production Planning of New and Remanufactured Products. Proceedings of the ASME 2013 IDETC/CIE.

Kwak, M.J., Hong, Y.S., Cho, N.W., 2009. Eco-architecture analysis for end-of-life decision making. International Journal of Production Research, 47 (22), 6233-6259.

Lambert, A.J.D., 2002. Determining optimum disassembly sequences in electronic equipment. Computers and Industrial Engineering, 43 (3), 553-575.

Liang, Y., Pokharel, S., Lim, G.H., 2009. Pricing used products for remanufacturing. European Journal of Operational Research, 193 (2), 390-395.

Ma, J., Kwak, M., Kim, H.M., 2014. Demand Trend Mining for Predictive Life Cycle Design. Journal of Cleaner Production, 68, 189-199.

Mangun, D., Thurston, D.L., 2002. Incorporating Component Reuse, Remanufacture, and Recycle into Product Portfolio Design. IEEE Transactions on Engineering Management, 49 (4), 479-490.

Ovchinnikov, A., 2011. Revenue and Cost Management for Remanufactured Products. Production and Operations Management, 20 (6), 824-840.

Ovchinnikov, A., Blass, V., Raz, G., 2014. Economic and Environmental Assessment of Remanufacturing Strategies for Product + Service Firms. Production and Operations Management, 23 (5), 744-761.

Rebitzer, G., Ekvall, T., Frischknecht, R., Hunkeler, D., Norris, G., Rydberg, T., Schmidt, W.-P., Suh, S., Weidema, B.P., and Pennington, D.W., 2004. Life Cycle Assessment: Part 1: Framework, Goal and Scope Definition, Inventory Analysis, and Applications, Environment International, 30 (5), 701-720.

Sodhi, M.S., and Reimer, B., 2001. Models for Recycling Electronics End-of-Life Products. OR Specktrum, 23 (1), 97-115.

SquareTrade, 2008. SquareTrade Research: iPhone More Reliable than BlackBerry, One Year In [online]. SquareTrade. Available from: https://www.squaretrade.com/htm/pdf/SquareTrade_PPhone_Study_1108.pdf [Accessed May 1, 2016].

SquareTrade, 2009. SquareTrade Research: One-Third of iPhones Fail Over 2 Years, Mostly From Accidents [online]. SquareTrade. Available from: https://www.squaretrade.com/htm/pdf/SquareTrade_iPhone_Study_0609.pdf [Accessed May 1, 2016].

Steeneck, D.W., Sarin, S.C., 2013. Pricing and production planning for reverse supply chain: a review. International Journal of Production Research, 51 (23-24), 6972-6989.

Umeda, Y., Kondoh, S., Sugino, T., 2006. Analysis of Reusability using 'Marginal Reuse Rate. Annals of the CIRPManufacturing Technology, 55 (1), 41-44.

Vorasayan, J., Ryan, S.M., 2006. Optimal Price and Quantity of Refurbished Products. Production and Operations Management, 15 (3), 369-383.

Wassenaar, H.J., Chen, W., 2003. An Approach to Decision-Based Design with Discrete Choice Analysis for Demand Modeling. Journal of Mechanical Design, 125 (3), 490-497. 